Journal of Comparative International Management

\title{
Physical Internet, Africa's Transport Infrastructure and Capacity Building
}

\author{
Radjabu Mayuto, Sègbédji Parfait Aïhounhin, Alexis Abodohoui and Elie \\ Chrysostome
}

Volume 20, Number 1, 2017

URI: https://id.erudit.org/iderudit/1055447ar

DOI: https://doi.org/10.7202/1055447ar

See table of contents

Publisher(s)

Management Futures

ISSN

1481-0468 (print)

1718-0864 (digital)

Explore this journal

Cite this article

Mayuto, R., Aïhounhin, S., Abodohoui, A. \& Chrysostome, E. (2017). Physical Internet, Africa's Transport Infrastructure and Capacity Building. Journal of Comparative International Management, 20(1).

https://doi.org/10.7202/1055447ar
Article abstract

This paper analyzes capacity building in transportation, logistics, and security in Africa. It is one of the first few research studies that reflects the reality of the development of Africa's infrastructural capacity for transport, based on the notion of the Physical Internet. Grounded on the analysis of the economic, environmental, and social impacts of transport logistics on the continent, the research sheds light on the deficit in infrastructure capacity of African countries. To this end, the study provides a set of recommendations for capacity building across African transport sectors. 


\title{
Physical Internet, Africa's Transport Infrastructure and Capacity Building
}

\author{
by
}

\author{
Radjabu Mayuto \\ Université Laval, Québec, Canada \\ Sègbédji Parfait Aïhounhin \\ Université Laval, Québec, Canada \\ Alexis Abodohoui \\ Université Laval, Québec, Canada
}

Elie Chrysostome

State University of New York, Campus of Plattsburgh, U.S.A.

\begin{abstract}
This paper analyzes capacity building in transportation, logistics, and security in Africa. It is one of the first few research studies that reflects the reality of the development of Africa's infrastructural capacity for transport, based on the notion of the Physical Internet. Grounded on the analysis of the economic, environmental, and social impacts of transport logistics on the continent, the research sheds light on the deficit in infrastructure capacity of African countries. To this end, the study provides a set of recommendations for capacity building across African transport sectors.
\end{abstract}

\section{Introduction}

In order to enable more efficient and sustainable logistics worldwide, researchers suggest applying the principles of the Internet to logistics and propose the conceptualization and operationalization of a Physical Internet (PI) in order to streamline logistics and transportation in all their forms (Montreuil, 2011; Montreuil, Meller, \& Ballot, 2013). Thus, like the Internet, the proposal of the Physical Internet would transform logistics so that there are routers, logistics centers and transit points that facilitate the movement and storage of physical objects in a very rational way (Sarraj, Ballot, \& Pan, 2012). In this context, objects and goods to distribute, store, and ship, should be packed in containers made for this purpose to minimize the loss of space and to ease their seamless standardized flow through the Physical Internet. This should notably help with moving from dedicated point-topoint and hub-and-spoke systems to an openly distributed intermodal transportation system, minimizing travel cost, time, energy consumption and greenhouse gas emissions (Montreuil, 2011; Montreuil et al., 2013).

In recent years, under the umbrella of the International Physical Internet Initiative, a number of projects have been undertaken to investigate the feasibility and operationalization of the Physical Internet. Research centers, companies and governments in Europe and North America have begun to recognize the power of 
the Physical Internet vision. China is launching its First Physical Internet Research Lab (Zhong, Huang, \& Lan, 2014). The Physical Internet is an open global logistics system. If at term, the aim is to have it implemented all across the world, including the Third World and developing countries, what about Africa? What is the current state of African logistics efficiency and sustainability? What about the logistics infrastructure?

To achieve the ambitious project of Physical Internet, it is important for African countries to also implement subsequent capacity building policies. In fact, capacity building is a conceptual approach that focuses on understanding the barriers that prevent people, governments, international organizations and non-governmental organizations from achieving their development goals. This approach promotes the improvement of the capacities of these actors while allowing them to measure the achievement of their development results (Ika \& Donnelly, 2017).

Overall, this approach is assessed at three levels according to the United Nations Development Program (UNDP, 2006). First, at the individual level, it requires the development of conditions that enable people to build and improve their knowledge and skills, while at the same time requiring them to put in place conditions enabling them to engage in the process of capacity building. Second, at the institutional level, it translates into support for institutions in developing countries, with a focus on governance and sound government management (UNDP, 2006). Third, at the societal level, it promotes the development of a more "interactive" public administration that integrates its own actions with the feedback it receives from the population as a whole. Indeed, the Organization for Economic Co-operation and Development (2006), in its Guidelines and Reference Series, seems to recognize performance outcomes regarding the role of capacity in human affairs and economic development when it states, as follows:

"Capacity" is understood as the ability of people, organisations and society as a whole to manage their affairs successfully. The definition is deliberately simple. It avoids any judgement on the objectives that people choose to pursue, or what should count as success in the management of their collective efforts. However, capacity is important because of its relationship to the performance of country systems, particularly in delivering basic goods and services, and providing a suitable policy and regulatory environment for development to take place. The relationship between capacity and performance in human affairs may be illustrated by analogy with the motor car. We are careful to maintain the car's engine, chassis, brakes, tyres, etc. - its capacity - because we value the safe and reliable transportation - the performance - that it provides. Development co-operation agencies are ultimately interested in the factors that make possible a strong performance in relation to developmental goals and the MDGs. This requires a clear understanding of the various determinants of that performance (OECD, 2006).

This paper also analyzes capacity building in transportation, logistics, and security in Africa. It assesses the economic, environmental, and social logistics of African countries. The sectors covered include airport infrastructure, roads, 
railways, inland waterways, maritime transport, and telecom. These sectors are presented via an analysis that highlights issues, weaknesses and threats, as well as strengths and opportunities. The analysis of each sector reveals how logistics is currently being implemented in Africa at the intra-continental (regional and national) and intercontinental levels.

Adhering to the Physical Internet initiative raises the crucial issue of skills related to specific modern logistics of the transport domain. In Africa, however, the poor quality of infrastructure is due, among other things, to evils known as endemic corruption (Zekos, 2004), but also to the lack of authorities' capacity to lead the destinies of nations, or to negotiate and finance public contracts. Often neither these authorities nor their advisors possess the necessary skills to make favorable strategic decisions in infrastructure contracts. Depending on their bargaining power, competent authorities should be able to combine the resources (human, financial, material, intangible) and skills available to them to make informed choices based on the following strategic options (Su et al., 1999): undertaking oneself or "Doing Alone", entrusting to others or "Make Doing", cooperating with others or "Doing With", or "Not Doing".

So the management of infrastructure acquired through massive investments requires having the adequate expertise on hand. Research is certainly a major contributor to innovation, generating a flow of technical concepts which, to properly implement, require continual renewal of the pool of technical competencies. Teaching and professionalization alike can also help build capacity at the national level through skills transfer. Thus, capacity building is part of the capacity imperatives for infrastructure development and performance in Africa- especially since the New Partnership for Africa's Development (NEPAD) has identified capacity constraints as a major obstacle to sustainable development. All sides acknowledge that without sufficient country capacity, development efforts in many of the poorest countries are unlikely to succeed, even if they are supported with substantially enhanced funding (OECD, 2006). As a result of this research, emphasis is placed on building capacity.

The present study is one of the first that reflects the reality of the development of Africa's infrastructural capacity for transport, based on the notion of the Physical Internet. Based on the analysis of the economic, environmental, and social impacts of transport logistics on the continent, the research sheds light on the deficit in infrastructure capacity of African countries. To this end, the study provides a set of recommendations for capacity building across African transport sectors. The rest of the paper is structured in six parts. Section two presents the theoretical background of this work. Section three presents a literature review. Section four describes the research methodology. Section five displays the results and analysis. Section six displays the discussion. Section seven presents the strategies for capacity building in Africa's transport infrastructure and Physical Internet. Finally, section eight is devoted to the conclusion, which provides a framework for the conditional implementation of the Physical Internet in Africa. 


\section{Theoretical Background and Conceptual Framework}

Montreuil et al. (2013, p. 152) defines the Physical Internet (PI or $\pi$ ) as 'an open global logistics system founded on physical, digital and operational interconnectivity through encapsulation, interfaces and protocols'. The Physical Internet has been introduced as a response to the Global Logistics Sustainability Grand Challenge to improve, by an order of magnitude, the economic, environmental and social efficiency and sustainability of the way physical objects are moved, stored, realized, supplied and used across the world, indeed of logistics in its broadest sense (Montreuil, 2009, 2011).

Montreuil et al. (2013) present a set of eight foundations of the Physical Internet: (1) it is a means to the end of logistics efficiency and sustainability, not an end by itself; (2) it is an open global logistics system; (3) it is founded on universal digital, physical and operational interconnectivity; it exploits (4) goods encapsulation, (5) standard smart interfaces and (6) standard coordination protocols; (7) it enables interconnected logistics, indeed a global open logistics web; and (8) it is driven by innovation.

The Physical Internet aims to positively affect logistics efficiency and sustainability. Logistics is efficient when it serves the needs for moving, storing, realizing, supplying, and using physical objects with minimal overall economic, environmental, and societal resources. It is sustainable when it is capable of maintaining high economic, environmental and societal performance over the long run, capable of facing the risks and challenges associated with a dynamic, changing and fast-evolving context, and contributing to a better world for future generations (Montreuil et al., 2013, p. 153). In essence, efficiency is about minimizing the resources required to satisfy logistics needs, while sustainability is about minimizing the negative burden of logistics outcomes.

The goal of improving logistics efficiency and sustainability is addressed by the Physical Internet via the achievement of the following environmental, economic and societal objectives (Montreuil et al., 2013; Montreuil, Rougès, Cimon, \& Poulin, 2012). From an environmental perspective, the objective is to sustainably and by an order of magnitude reduce greenhouse gas emissions, energy consumption, pollution, and waste of materials induced by logistics, indeed contributing to a greener planet.

From an economic perspective, the target is to sustainably and by an order of magnitude reduce the global economic burden of logistics while generating substantial business productivity gains. Indeed, logistics is a high percentage of the gross domestic product of most countries so gains in reducing logistics-induced wastes would have a significant impact on the productivity and competitiveness of companies and countries.

From a societal perspective, the objective is threefold. First, it is to substantially and sustainably increase the quality of life of logistics workers, improving their toooften precarious work conditions and reducing the currently high turnover rates across the industry. Second, it is to reduce the congestion inflated by logistics- 
induced freight transportation. Third, it is to enable easier, cheaper and more reliable accessibility and mobility of physical objects across the world.

The aforementioned characteristics, foundations and objectives contribute to making the Physical Internet a global system, being both worldwide and multi-scale (Montreuil et al., 2013). Thus, countries wishing to engage in the project as envisioned must already possess logistics whose nature and functionality would allow them to pursue and meet the objectives described above.

In this respect, the situation of the African continent calls for an assessment of the state of its infrastructure, with a view to identifying the actions needed to update the existing infrastructure to the standards required to meet the Physical Internet objectives.

Since this paper involves assessing the readiness of African countries for PI, to structure this assessment we have developed a conceptual framework depicted in Figure 1.

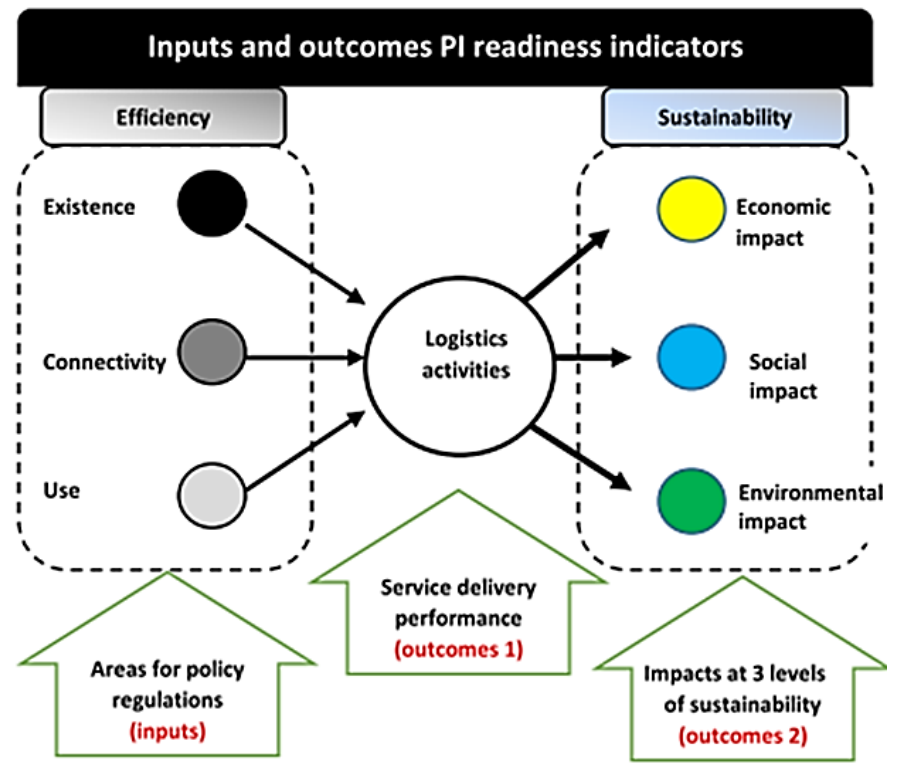

Figure 1. Conceptual framework for PI readiness assessment.

Adapted from Arvis et al., 2014.

The left side of the framework focuses on input-oriented efficiency concepts. It considers the areas for policy regulations regarding the main infrastructural inputs to the supply chain: the existence of transport sector infrastructure; the use of transport infrastructure (for trade) and logistics services (McKinnon et al, 2013; Ballot \& Fontane, 2008); and connectivity of logistic service networks, resulting in ease of arranging competitively priced shipments by tapping into a wide option of routes and modes (Christie et al., 2013; Sarraj et al., 2012). The interconnection 
of logistics networks is a sine qua none condition enabling the Physical Internet (Sarraj et al., 2012).

The right side of the framework focuses on outcome-oriented sustainability concepts, more specifically on their economic, social and environmental impacts. At the center of the framework lies the logistics activities, inducing service delivery performance.

Assessing the readiness of a country for the Physical Internet using the conceptual framework of Figure 1 involves significant data, requiring a rigorous methodology to capture the network flow, resources, and its impacts as a whole. The table below encompasses several terminologies for the different sectors studied in this paper.

Table 1. Sectoral terminologies used in this study.

\begin{tabular}{|l|l|}
\hline \multicolumn{1}{|c|}{ Commonly used terms } & \multicolumn{1}{c|}{ Sector (as termed in our study) } \\
\hline Inland Waterways & River \\
\hline Railways & Rail \\
\hline Maritime transport & Sea \\
\hline Roads & Road \\
\hline Airport Infrastructure & Air \\
\hline Telecom & Telecom \\
\hline
\end{tabular}

Source: Own investigations.

\section{Literature Review}

After the organization of production, the transport sector appears to be an essential factor in the development of economies. However, if this sector appears to be one of the keys to progress, its control requires appropriate expertise. This is particularly true since there is an important link between transport and localization, urban and regional development as well as economic growth (Quinet \& Vickerman, 2014). Moreover, policy makers involved in the provision and regulation of transport and researchers interested in transport planning and policy should live up to the aspirations that legitimize investment in transport infrastructure. The professionalization of official actors becomes a priority for countries that value competence. A skill has no material existence regardless of the person who implements it. Africa therefore needs qualified professionals (Le Boterf, 2007) in relation to the situation of the infrastructure it acquires, renews, and plans to build. A new approach to engineering is needed.

A widely-accepted definition describes capacity as "the ability of individuals, organizations, and the community as a whole to manage their affairs successfully." It encompasses the ability to create, understand, analyze, develop, plan, achieve goals, reflect on outcomes, move towards a vision, change, and transform (FAO, 2013). The AU / NEPAD Capacity Building Strategic Framework defines capacity as "the ability of individuals, groups, organizations, institutions and societies to define, articulate, engage and sustainably realize their vision or Development objectives based on their own resources" (UA and NEPAD, 2012). 
Inadequate capacity is an ongoing challenge that limits programs and projects that can promote inclusive economic growth, sustained development and integration (ACBF, 2016, p.5). To ensure that priority programs for the transformation of transport infrastructure in Africa are implemented in a sustainable way in light of the Physical Internet vision, capacity building must be at the heart of the transformation process.

The definition, as adopted in the FAO strategy for capacity building, explains capacity building as a process whereby individuals, organizations and the community as a whole liberate, create, strengthen, adapt and preserve capabilities over time. In addition to technical aspects, capacity-building encompasses political and social aspects and should take into account the following three dimensions: individual, organizational, and systemic (enabling environment) (FAO, 2013).

One of the major challenges for a new transport infrastructure is that both the problems faced and the skills necessary change as the country system moves from one stage of development to another. Therefore, understanding the changes required as a consequence of growth is as vital as human resource skills and capabilities, as approaches thought desirable for one (previous) technical stage will be inappropriate for another (reached) stage. Paving the road to sustainable and efficient transport requires the governance of innovation to foster sustainable performance. The quest for innovation is consistently at the top of the agenda for policy makers around the globe, on a supra-national level, as well as for the nation states and all the way down to debates in local governance and policy boards (Nilsson et al., 2012). Africa is no exception. This high level of awareness can be attributed to the ACBF (2016) effort which has just completed a study on the capacity-building imperatives for the AU Agenda 2063 in recognition of the pivotal role of capacity in its effective implementation.

The ACBF Capacity Building Team developed four capacity categories to address capacity needs for Agenda 2063: (1) four aspects of the operational capacities of the organizations: Human Capacity, Institutional/Organizational Capacities, Work Systems and Processes, Access to Information and Knowledge; (2) capacity for change and transformation (leadership for transformation (including vision), the ability to change mindsets, technological predisposition and information and communication technologies (ICT), commitment to invention and innovation, risk management capacities, appropriation of decision-making, etc.); (3) composite capacities (a combination of four areas of capacity (planning, facilitation, knowledge and risk management, funding, program management and development) that require operators to pool knowledge and information and use them in ways that are multidisciplinary and multi-faceted); and (4) essential, technical and sectoral competencies (ACBF, 2016). This last category includes technical or specialized skills and knowledge essential for Africa, as well as expertise in the following areas: health; mining; finance; TIC; energy; engineering; infrastructure; research institutions; water resources and management; science, technology and innovation (STI). As can be seen, this latter category is our focus.

Following the analysis of the content, objectives and activities of Agenda 2063, the ACBF Team advances three key strategic dimensions that help answer the question: "Capacity for what?" These are: recasting the African mindset into the concept of African ownership (dimension 1), identifying initial continental "flagship 
projects”, key development goals of member states, and special development activities and initiatives (dimension 2), and scenario building/risk management and anticipating exigencies of the future (dimension 3). Hence, going beyond the production of one "umbrella" capacity development plan (CDP), the Capacity Team proposes templates that develop multilevel plans at the continental, regional, and national levels, and multistakeholder needs for plans that address the CD needs of key stakeholder groups to enhance the planning of initial CD efforts.

Furthermore, the notion of performativity - in the sense attributed to it by JeanFrançois Lyotard (1979), that is to say, as a discourse, a logic aimed at promoting technical efficiency among the actors within a field or a given organization - is useful for reflection. As human beings performing in all spheres of life, there are many smaller contexts which we act within. These roles legitimate knowledge and courses of action in their limited contexts. By fragmenting life into a thousand localized roles, each with their particular contexts for judging actions and knowledge, we experiment with the nature of the modern social bond. Our effectiveness is judged in the context of how well we perform in each of these many limited roles. Therefore, what legitimates knowledge in the postmodern condition is how well it performs, or enables a person to perform, in particular roles. This criterion forms the basis of Lyotard's "performativity" legitimation of knowledge and action. In a cybernetic society, knowledge is legitimated by how performative it is, if it effectively minimizes the various required inputs for the task, and maximizes the desired outputs. This is an intuitively compelling notion of our current society. Knowledge and decision-making is for the most part no longer based on abstract principles, but on how effective they are at achieving desired outcomes (Lyotard, 1979). Since performativity increases the ability to produce performance, it also increases the ability to be competent. The same has been said of the relationship between competence and performance.

If the performativity of the supposed social system is taken as the criterion of relevance (that is, when the perspective of systems theory is adopted), higher education becomes a subsystem of the social system, and the same performativity criterion is applied to each of these problems. The desired goal becomes the optimal contribution of higher education to the best performativity of the social system. Lyotard points out that the principle of performativity plays an increasingly important role in the world of research. Capitalism forces the State and the enterprise to favor the issue of performativity, that is to say, the best input-output ratio.

The organizational norms that prevail in companies enter laboratories of applied study: hierarchies, work decisions, the training of teams, the estimation of individual and collective returns, the development of salable programs, the search for clients, etc. (Lyotard, 1979: 75). The process of capacity building (CT) is a valuable breeding ground for the attractive human capital of foreign investment, in addition to the progressive upgrading of infrastructure.

Given the weight of institutional and organizational cultures in CR, the unique nature of each country's situation tends to become a determining factor in the development and implementation of CR programs. To be successful, the intervention processes must be finely personalized according to the organizational and institutional environment of the country concerned. 
As the manner in which they are manifested will differ according to the extent of the competencies of the ministry, their implications for capacity building needs (RCs) also differ. The analytical framework suggests that four types of capacity are needed:

- Institutional capacities or rules of the game.

- Organizational capacities or structures that allow for the implementation of these rules of the game through organizational arrangements.

- Individuals’ ability to achieve organizational intent.

- The technical capabilities and knowledge base that officers can use to fulfill their planning and management missions.

\section{Methodology}

The Physical Internet is an emerging concept for which scientific research is still at the level of conceptualization. The literature has only begun to lay the beacons that guide research in this area. This means that the writings are still rare. This is why we conducted the literature review in both academic and non-academic channels, so as to better grasp the real situation and consider the applicability of the Physical Internet project in Africa.

Content analysis was chosen as the method of analysis, because it is generally considered a useful measurement technique in Social Sciences (Okazaki, 2004: 86). The technique is useful to social scientists who evaluate historical documents, newspaper stories, political speeches, interviews, diplomatic messages, psychological journals and official publications (Weber, 1990: 5).

The information collected was analyzed at several levels (images, words, statistics, etc.), creating a wide range of avenues for research (Lombard et al., 2002: 588) and interpretation. Content analysis refers to the material rather than a summary of the current literature. Other documents consulted were developed by specialized agencies of the United Nations such as the Economic and Social Commission for Africa, the International Office for Transport, and the United Nations Environment. For additional data, we also consulted the archives of ministries, organizations of African civil society, and newspapers that are also rich in information. The interpretation of these documents is the basis of our analysis.

To do this, we first decomposed the material into its constituent African countries before looking at each region in terms of economic, social and environmental as well as inner and outer connectivity considerations. This allowed us to subsequently aggregate it into a continental outlook on the reality of the logistics infrastructure.

\subsection{Document analysis protocol}

This protocol is a compound of the collection and evaluation of different selected documents. 


\subsubsection{Collection, preparation and filing of documents}

With reference to our research topic, we proposed to search and analyze documents such as the atlas, magazines, scientific articles, etc. All documents necessary for the implementation of this work have been made available. In order to prepare reports on the content analysis, we have listed and ranked the documents of our bibliography in alphabetical order.

\subsubsection{Evaluation and preliminary reading of documents}

Content analysis requires an assessment of the documents to be analyzed (Depelteau, 2010). It involves reading the contents of documents, identifying initial ideas revealed by these documents, and analyzing them in a rigorous way. A preanalysis was made to allow us to identify some key ideas to guide the entire analysis toward achieving the objectives. We performed an evaluation of the documents, checking their origin and their status. This notably involved ensuring that the documents indeed had information pertinent to helping us refine our work. The content of each document was briefly assessed versus the accuracy of its information.

\subsubsection{Selection and definition of codes}

According to Depelteau (2010), codes “[are] applied to groups of words identifying symbols, collect and classify the different information obtained from interviews, observations, or other means ... they can also be units of meaning, that is to say a special atmosphere situated in the broader context of the document ... they must be comprehensive, clear, objective, relevant, consistent and numbered". As part of this work, the following were available as examples of valid codes for analysis. These codes combine sequenced numbers, numbered letters followed by 2 sets of numbers. Each component has a special meaning.

- $01,02, \ldots,=$ numbers of the various documents

- $\mathrm{A} 1=$ All relevant and revealing statements designating the rail;

- A2 = All relevant and revealing statements designating the river;

- $\mathrm{B} 1$ = All relevant and revealing statements designating the sea;

- B2 = All relevant and revealing statements designating telecommunications;

- $\mathrm{C} 1$ = All relevant and revealing statements designating the air;

- $\mathrm{C} 2$ = Any relevant and revealing statement designating the road;

- Any figure " $\mathrm{X}$ " = page number where the information was found;

- Any figure "Y" = paragraph number where the information was found.

One document can, for example, have the following code: 01-A1-C1-18-02; meaning Document 01 - Statement meaning “rail” - statement meaning “air” - Page 18 of the report - Paragraph 02. 


\subsubsection{Analysis and interpretation of data}

This is the last step of our methodology. This part was made on the basis of a system based on a critical analysis of the results from the content analysis of the studied documents and articles. Analysis and interpretation of data collected in the various documents allowed us to realize, for example, that North Africa and Southern Africa are the two regions in Africa that have the necessary characteristics to consider implementing the Physical Internet. Other economic and infrastructural studies validate this finding (RMB, 2013; ICA, 2013). This has helped us to propose the continuation of our work, the cartography of the logistics implications of the Physical Internet on the continent.

Also, to analyze and interpret the data collected, we designed a scorecard system, which allowed us to investigate the logistics of the entire African continent. As well, the rail, sea, river, air, road, and telecommunications sectors in each country on the continent were reviewed through the amplitude of logistics movement indicators (existence, connectivity, and use), characteristics of "doing business”, environmental impact, and social impact based on the following criteria:

- Indicator turns green if the performance of the sector belongs to the interval [56-66].

- Indicator turns yellow if the performance of the sector belongs to [46 - 56].

- Indicator turns red if the performance of the sector belongs to [36 - 46].

- Indicator turns gray in the absence of information on the sector's performance.

- When the indicator is not applicable to the sector concerned, a square is used in place of the evaluation.

Similarly, the calculation of the average of each country and the overall average of each sub-continent followed the same scoring system.

As regards the interpretation of the scorecard, different colors denote the performance level of each segment. This performance is evaluated based on six indicators: sectoral existence of infrastructure, effective connectivity sector use (activity), sectoral Doing Business Ranking (World Bank, 2013), social impact, and environmental impacts. To this end, the green color with the sign $(+)$ means that the performance of the sector is satisfactory. The yellow color marked (O) means that the sector's performance is moderately satisfactory. Red with the sign (-) means that the sector's performance is unsatisfactory. In the absence of information, sector performance is not rated and the indicator is gray. In non-applicable cases, a small square is registered instead of the evaluation. Moreover, green is distinguished with a light green color (neon) when the performance of the country is very satisfactory and a dark green color for a satisfactory performance.

In this section, we introduce the sample, the methods, and the measures used in this paper for PI readiness assessment.

Sample. Data collection for the PI readiness assessment was a challenging process as such an assessment had never been done before. We developed a methodology to 
collect materials for the literature review. In this study, we reviewed 54 African countries using the available literature that could enhance the understanding of the PI relevance for regional development. Documents were collected according to a number of criteria. To be included in this study, a document had to (1) deal with Africa, (2) be formally published by a world-renowned organization or institution, (3) include empirical study or sustained reflection on African infrastructure, (4) deliberate on the logistical, economic, social, and environmental benefits to Africa, (5) include a study or sustained reflection analysis of logistics performance in Africa.

Since it was necessary to evaluate historical documents, newspaper stories, political speeches, interviews, diplomatic correspondence, official publications (Weber, 1990: 5), “content analysis” was considered as a method (Okazaki, 2004). The information collected was varied in nature (images, words, statistics, etc.), creating a wide range of avenues for research (Lombard, Snyder-Duch, \& Bracken, 2002: 588) and comparative study.

For this purpose, codes (Depelteau, 2010) were applied to groups of words to identify symbols, and collect and classify the different information obtained from books, academic publications, magazines, journals, etc. [...]; they could also be units of meaning. In doing so, the information was put into classes representing African infrastructure sectors. Indeed, some information could belong to several classes, and alphanumeric codes allowed it to be distinguished as meaningful multisectoral data.

Methods. As elsewhere in the world, logistics involvement in PI in Africa passes through existing sectoral logistics, operating within an amplitude which promotes (much, little or no) efficiency and sustainability in each country. To understand this complexity and to deal with the great variety of contexts, three methodological tools were built: a composite indicator of the applicability of PI (forthcoming RPI index), a palette color-based criterion, and a scorecard system. The composite indicator of the applicability of PI organizes the concepts, variables and indicators dedicated to evaluation. It is a measure of the readiness for the PI (see Table 1). The criterionreferenced color palette or palette provides a visual way to evaluate a sector, country or continent on the basis of the included indicators. In this sense, it helps to read the results of the evaluation (Table 3). The scorecard system brings elements together in a coherent mold (black box) by crossing on the one hand indicators and on the other hand the object to assess such as sector, country, region or continent, as appropriate. Hence, all enabled us to investigate the logistics at the continental level, analyzing and interpreting collected data.

To proceed as described above, a conceptual framework of the system was necessary. Portrayed in Figure 2, it is derived from the operational framework established by Porter and Stern (2013) for the Social Progress Index. 


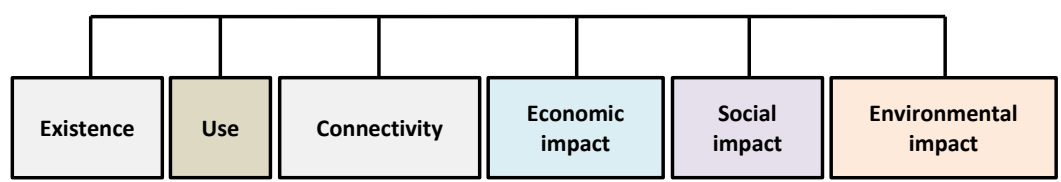

Figure 2. A framework for measuring Physical Internet readiness.

The processing device is here configured to combine two separate factors (efficiency, sustainability) to obtain the readiness of PI as one measurable body. In addition, six sectors were selected: road, rail, inland waterway, maritime, air, and telecommunications. Our aim through this methodological approach was to estimate "the readiness" of the African continent for the realization of the vision as embodied by this new concept. Such a methodology was appropriate to determine the feasibility of PI for a given country.

Measures. The Physical Internet is an emerging concept for which research is still at the conceptualization level. Empirical studies to provide refined variables and indicators for operationalization are still scarce. Background variables were selected based on the existing literature and relevant collected documents from official databases (Arvis et al., 2014). (i.e. UNCTAD, 2010; World Bank, 2014).

The framework is built on the assumption of operating logistical infrastructure issues in terms of economic, social and environmental effects. For a given sector, this approach puts in phase the existence of such infrastructure, its use and its connectivity (intra and inter-sectoral).

The six core components for the readiness of Physical Internet for a sector/country are:

- The existence of transport sector infrastructure, which states the nature and the condition of the infrastructure, was rated from "poor" (0) to "excellent” (1).

- The use of transport infrastructure (for trade) and logistics services. Since these depend on the competence and quality of logistics services in a given country, the Logistics Performance Index (LPI) was used (adapted LPI was obtaining by using the ranking rather than the score). Adapted LPI was rated from "poor" (0) to "excellent" (1).

- Connectivity was divided into two sub-indicators: domestic and global connectivity. The former took into account at the national level the intrasectoral and the inter-sectoral connectivity. The latter was devoted to distinguishing a landlocked country from a coastal country. While both indicators were rated from "poor" (0) to "excellent" (1), coastal countries embodied the Liner Shipping Connectivity Index (UNCTAD, 2010).

- The economic impact referred to a result of the use of transport infrastructure at a societal level. Following the same procedure as for LSCI, the Doing Business Ranking (DBR) assigned to measure this impact was rated from "poor" (0) to “excellent” (1). 
- The social impact was the average of four components including the country population accessibility, the country population mobility, sectoral employment, and cultural impact of the sector on the country's population. All sub-indicators were rated in the same way, from "poor" (0) to "excellent" (1).

- The environmental impact contained two divergent but complementary components: logistics pollutants emission and mitigation responses from the government. Those two indicators were not rated in the same fashion. While the second was rated from "poor" (0) to "excellent" (1) the first was reversescaled from "poor" (1) to "excellent” (0).

Furthermore, all measures are summarized hereafter in the synthesis Table 2.

Table 2. Indicators grid for measuring Physical Internet readiness.

\begin{tabular}{|c|c|c|c|}
\hline $\begin{array}{l}\text { Core } \\
\text { Performance } \\
\text { Components }\end{array}$ & Component Variable & Indicator & Measurement \\
\hline Existence & Existence & Existence of transport channel & Likert \\
\hline \multirow[t]{6}{*}{ Connectivity } & Domestic & & Average \\
\hline & Domestic intra-sectorial & $\begin{array}{l}\text { Domestic intra-sectorial } \\
\text { connectivity }\end{array}$ & Likert \\
\hline & Domestic inter-sectorial & $\begin{array}{l}\text { Domestic inter-sectorial } \\
\text { connectivity }\end{array}$ & Likert \\
\hline & Global & & Average \\
\hline & landlocked country & & Likert \\
\hline & coastal country & $\begin{array}{l}\text { Liner Shipping Connectivity Index } \\
\text { (LSCI) }\end{array}$ & Likert \\
\hline Use & $\begin{array}{l}\text { Logistics Performance } \\
\text { Index (LPI) }\end{array}$ & Logistics Performance Index (LPI) & Adapted LPI \\
\hline $\begin{array}{l}\text { Economic } \\
\text { Impact }\end{array}$ & Doing Business & Doing Business Ranking (DBR) & Adapted DBR \\
\hline \multirow[t]{5}{*}{ Social Impact } & & & Average \\
\hline & Accessibility & Country accessibility social impact & Likert \\
\hline & Mobility & Country mobility social impact & Likert \\
\hline & Employment & Country employment social impact & Likert \\
\hline & Cultural & Country cultural social impact & Likert \\
\hline \multirow{3}{*}{$\begin{array}{l}\text { Environmental } \\
\text { Impact }\end{array}$} & & & Average \\
\hline & Pollutants emission (-) & Pollutants emission adapted index & Likert \\
\hline & Mitigation responses (+) & Mitigation responses adapted index & Likert \\
\hline
\end{tabular}

Source: Own investigations. 
In short, the indicator measurement is made at two levels (national and sectoral) depending on the type of indicator and available data. This is the case in the Doing Business and connectivity indicators. They are assessed at the national level, where the realized values used are from secondary data. With regard to indicators measured at the sector level such as the existence and use (utilization), the realized values stem from an analytical assessment carried out by the authors. In either case, the refinement of the analysis and measurement of variables was made based on the Likert scale as proposed by Rosenberg (1965).

The scores calculating method and its interpretation followed a phased approach. Step 1: Each indicator as defined in the table above, is used to evaluate an area and has a value ranging from 0 (lowest) to 1 (highest). This value will be equivalent to an interval Likert scale with eight (8) items as described in the table below. The score is the average value of the interval considered. This calculation is the same for all indicators except the use (adapted LPI) and economic impact (adapted DBR), for which the operation is different. In this case, the realized value obtained after the analysis of the "rank countries" is the complement to 1 of the ratio of the country's ranking (r) and the total number of countries in each schedule (n) according to formula 1 below.

$$
V r=1-\frac{r}{n} \text { with } 0 \leq V r \leq 1
$$

Finally, and as in the first case, it also relates to the end of the color scale notification. These indicators are labeled 'adapted' due to this arithmetic processing. Step 2: we computed the average line, possibly to find the average of the study area (optional). Step 3: each indicator now having its value for an area, the calculation can be extended to all six sectors whose average will be that of the country. In other words, the same grid was used to compute the realized values of sectoral indicators at the national level. Also, the calculation of the performance of different regions, and even the continent, followed the same procedure.

The criterion-referenced full color evaluation palette is a visual medium for assessing the performance of a sector or a country or a continent on the basis of indicators defined in the previous measurement grid. The result from this assessment on the eight point Likert scale is a value obtained, which varies between 0/8 and 8/8. These fractional intervals, which can be read as consistent with decimal values, are exactly on an eight-color palette scaled from 0 to 1 . In this sense, unlike digital scale appreciation or descriptive appreciation, as a rating scale the palette allows an easy reading of the evaluation result by means of the colors. Table 3 presents the previously described characteristics. As an application compatible with all levels of analysis, the color scale for determining the rate of readiness for the PI initiative is a relatively simple and reliable tool. Two default colors should be noted: when the evaluation is not applicable or there is a lack of data, white and gray squares are respectively used. 
Table 3. Palette (colors) applicable indicators.

\begin{tabular}{|c|c|c|c|c|}
\hline Decimal Intervals & Fractional Intervals & Min. Value & Max. Value & Applicable Color \\
\hline$\{0,875-1,000\}$ & {$[7 / 8-8 / 8]$} & 0,875 & 1 & \\
\hline$\{0,750-0,874\}$ & {$[6 / 8-7 / 8]$} & 0,75 & 0,874 & \\
\hline$\{0,625-0,749\}$ & {$[5 / 8-6 / 8]$} & 0,625 & 0,749 & \\
\hline$\{0,500-0,624\}$ & {$[4 / 8-5 / 8]$} & 0,5 & 0,624 & \\
$\{0,375-0,499\}$ & {$[3 / 8-4 / 8]$} & 0,375 & 0,499 & \\
\hline$\{0,250-0,374\}$ & {$[2 / 8-3 / 8]$} & 0,25 & 0,374 & \\
\hline$\{0,125-0,249\}$ & {$[1 / 8-2 / 8]$} & 0,125 & 0,249 & \\
\hline$\{0,000-0,124\}$ & {$[0 / 8-1 / 8]$} & 0 & 0,124 & \\
\hline & & & & \\
\hline Not applicable & Not applicable & & Not applicable & \\
\hline Missing data & Missing data & & Missing data & \\
\hline & & & & \\
\hline
\end{tabular}

Source: Own investigations.

The first two tools are used in the scorecard system. Integrating the embedded measuring grid and the reading grid or criterion-color palette, this system completes the evaluation and therefore provides the criteria-based evaluation (criterionreferenced assessment) of the sector, country, region or continent on the indicators. Following Legendre (1988), we define the criterion-referenced assessment as an evaluation mode where logistics performance of a sector/country in performing a transportation task is compared to a threshold or a criterion for success, determined in the formulation of one or more objectives, regardless of the performance of any other sector/country.

This concept eases the interpretation of the scorecard, combining indicators with the performance of a sector that is measured and analyzed based on the following criteria:

1. The indicator turns sky blue, if the performance of the sector belongs to the interval $\left[\frac{7}{8} ; \frac{8}{8}\right]$

2. The blue indicator changes to dark blue if the performance of the sector belongs to the interval $\left[\frac{6}{8} ; \frac{7}{8}\right]$

3. The indicator turns neon green if the performance of the sector belongs to the interval $\left[\frac{5}{8} ; \frac{6}{8}\right]$

4. The indicator turns dark green if the performance of the sector belongs to the interval $\left[\frac{4}{8} ; \frac{5}{8}\right]$

5. The indicator turns bright yellow if the performance of the sector belongs to the interval $\left[\frac{3}{8} ; \frac{4}{8}\right]$ 
6. The indicator turns dark yellow if the performance of the sector belongs to the interval $\left[\frac{2}{8} ; \frac{3}{8}\right]$

7. The indicator turns red if the performance of the sector belongs to the interval $\left[\frac{1}{8} ; \frac{2}{8}\right]$

8. The indicator turns dark red if the performance of the sector belongs to the interval $\left[\frac{0}{8} ; \frac{1}{8}\right]$

9. The indicator turns gray in the absence of information on the sector's performance.

10. When the indicator is not applicable to the industry, a square is used in place of the evaluation.

The different colors indicate the level of performance of each segment as assessed according to six indicators: existence of infrastructure, infrastructure use, and connectivity of the infrastructure, as well as Doing Business, social impact, and environmental impact associated with the use of infrastructure. The color of a sector's performance indicates its position with respect to the applicability of the PI. The lower we fall on the color scale - from blue (top) to red (low) ( $\downarrow$ ) - the less favorable the sector to the implementation of the PI and vice versa. Accordingly, sky blue with the number 8 ( $1^{\text {st }}$ class, level 8$)$, means that the performance of the sector concerned is excellent; dark blue with number 7 ( $2^{\text {nd }}$ class, level 7 ) is very satisfactory; light green marked 6 ( $3^{\text {rd }}$ class, level 6) is quite satisfactory; dark green with 5 ( $4^{\text {th }}$ class, level 5$)$ is satisfying, light yellow marked 4 ( $5^{\text {th }}$ class, level 4$)$ is moderately satisfactory; dark yellow with 3 ( $6^{\text {th }}$ class, level 3$)$ is moderately unsatisfactory; bright red with number 2 ( $7^{\text {th }}$ grade, level 2$)$ is unsatisfactory; dark red with 1 ( $3^{\text {rd }}$ class, level 1 ), means that the sector's performance is poor. In the absence of information, sector performance is not rated and the indicator is gray. In inapplicable cases, a small square is registered instead of the evaluation.

\section{Results and Analysis}

As regards the interpretation of the scorecard, different colors denote the level of performance of each segment. This performance was evaluated based on six indicators: sectoral existence of infrastructure, effective connectivity, sector use (LPI), sectoral Doing Business (World Bank, 2013a; 2013b), social impact, and environmental impacts (Table 2). A country assessment created from the average of all the infrastructure sectors together showed that the continent presents a mosaic of contexts reflecting different applicability levels within 50 countries. In spite of this color variance, African countries neither reach the top levels (7 and 8) nor fall to the lowest levels. If we consider level 5 as the threshold of readiness for PI, African countries are split into two groups, of which 10 emerged as ready and 40 (80\%) were below the pass mark. That is the hidden part (submerged) of the iceberg.

From the results of different sectors (rail, sea, river, air, road, telecommunications), we determined performance levels which are indicated by a color on the palette. In doing so, we put all considered countries' data into a map of Africa as displayed in Figure 2, which highlights not only the current state of logistics, but also in a pictoral way, the readiness of the countries relative to the operationalization of the Physical Internet. 
Table 4. Cluster-based results of Africa's readiness for IP assessment.

\begin{tabular}{|c|c|c|c|c|}
\hline Level & Countries & $\begin{array}{l}\text { Dominant Region } \\
\text { (\% of countries } \\
\text { within cluster) }\end{array}$ & $\begin{array}{l}\text { Indicator observation } \\
\text { (key results) }\end{array}$ & $\begin{array}{l}\text { Sector } \\
\text { observation } \\
\text { (main facts) }\end{array}$ \\
\hline \multicolumn{5}{|l|}{8} \\
\hline \multicolumn{5}{|l|}{7} \\
\hline 6 & Morocco, South Africa. (2) & & $\begin{array}{l}\text { S: Use }(.750), \text { Economic } \\
\text { Impact }(.750) \\
\text { W: Environmental } \\
\text { Impact }(.380)\end{array}$ & $\begin{array}{l}\text { S: Telecoms } \\
(.648) \\
\text { W: River } \\
(.552)\end{array}$ \\
\hline 5 & $\begin{array}{l}\text { Algeria, Tunisia, Egypt, } \\
\text { Ghana, Burkina Faso, } \\
\text { Rwanda, Botswana, } \\
\text { Mauritius. (8) }\end{array}$ & $\begin{array}{l}\text { North Africa (3) } \\
(3 / 8,37 \%)\end{array}$ & $\begin{array}{l}\text { S: Economic Impact } \\
(.671) \\
\text { W: Use }(.390)\end{array}$ & $\begin{array}{l}\text { S: Telecoms } \\
(.546) \\
\text { W: Rail } \\
(.487)\end{array}$ \\
\hline 4 & $\begin{array}{l}\text { Senegal, Cote d'Ivoire, Benin, } \\
\text { Nigeria, Equatorial Guinea, } \\
\text { Ethiopia, Uganda, Kenya, } \\
\text { Burundi, Tanzania, Namibia, } \\
\text { Mozambique, Madagascar. } \\
\text { (13) }\end{array}$ & $\begin{array}{l}\text { East Africa (5) } \\
(5 / 13,38 \%)\end{array}$ & $\begin{array}{l}\text { S: Existence }(.615) \\
\text { W: Economic Impact } \\
(.235)\end{array}$ & $\begin{array}{l}\text { S :Telecoms } \\
(.443) \\
\text { W: Rail } \\
(.377)\end{array}$ \\
\hline 3 & $\begin{array}{l}\text { Mauritania, Mali, Sierra } \\
\text { Leone, Togo, Libya, N Sudan, } \\
\text { Gabon, Djibouti, Cameroon, } \\
\text { Congo, DR Congo, Zambia, } \\
\text { Angola, Gambia, Malawi, } \\
\text { Zimbabwe. (16) }\end{array}$ & $\begin{array}{l}\text { West Africa (5) } \\
(5 / 16,31 \%)\end{array}$ & $\begin{array}{l}\text { S: Existence }(.511) \\
\text { W: Economic Impact } \\
(.148)\end{array}$ & $\begin{array}{l}\text { S: Telecoms } \\
(.392) \\
\text { W: Road } \\
(.271)\end{array}$ \\
\hline 2 & $\begin{array}{l}\text { Guinea, Guinea Bissau, Niger, } \\
\text { Liberia, Chad, Eritrea, } \\
\text { Somalia, S Sudan, Swaziland, } \\
\text { Lesotho, Central African } \\
\text { Republic. (11) }\end{array}$ & $\begin{array}{l}\text { West Africa (4) } \\
(4 / 11,36 \%)\end{array}$ & $\begin{array}{l}\text { S: Existence }(.279) \\
\text { W: Economic Impact } \\
(.125)\end{array}$ & $\begin{array}{l}\text { S: Telecoms } \\
(.215) \\
\text { W: Rail } \\
(.110)\end{array}$ \\
\hline 1 & & & & \\
\hline
\end{tabular}

Source: Own investigations.

Accordingly, Africa's readiness for PI reveals striking differences across countries in their logistics performance and highlights variation within strengths and weaknesses of individual countries. As such, the results provide concrete priorities for both national and regional policy agendas and identify other countries to learn from.

African countries are classified in five clusters with the average score going from 0.645 up to 0.172 . Areas of strength include telecom and air, while weak performance areas consist of the rail system (0.110) and river (0.177). The highest points are scored in the areas that have to do with the existence of logistical infrastructures (0.628) and economic impact of their use (0.750). While the lowest points were scored at the level of economic impact (0.125), the use itself and the environmental impact are the weaknesses (0.343). In what follows, we are going to 
separately present the different clusters with their major characteristics, resulting from the assessment in this study.

The top two countries in Africa in terms of PI readiness are Morocco and South Africa. These two countries, closely grouped in terms of average cluster scores, are strong in telecommunications (0.648) and air (0.645), and are relatively weak in terms of rivers (0.552) and rail (0.578) logistics performance. Within this cluster, usage (0.750) and economic impact (0.380) are strong while environmental impact remains weak. Geographically, they score strongly across all PI dimensions. They symbolize the upper and the lower parts of the continent. They belong to the Level 6 cluster, which indicates a quite satisfactory readiness for the PI vision.

The remainder of the top ten includes a group of Northern African nations (Algeria, Tunisia and Egypt), Southern African and assimilated states (Botswana and Mauritius), as well as Western African countries (Ghana, Burkina Faso), and Rwanda. Together with the top two, these countries round out a distinct "top tier" of countries in terms of "readiness for PI" scores: the visible (emerged) part of the iceberg. Although these countries profit from the existence $(0.628)$ of some infrastructure (0.628) and a satisfactory economic impact (0.671), the documented problems are depicted by the weakness of logistics performance (0.380) and environmental impact (0.410). With Ghana as the standard-bearer, eight economies belong to the Level 5 cluster of dark green countries showing a satisfactory level for PI implementation.

A notch lower is a second tier of countries that first includes a large group of 13 thirteen light yellow countries, ranging from Senegal to Madagascar. With a domination of Eastern African countries, this group includes a number of Africa's leading (promising) economies in terms of GDP and population (Cote d'Ivoire, Equatorial Guinea, Kenya, Nigeria, Senegal) and others including Benin, Burundi, Ethiopia, Madagascar, Mozambique, Namibia, Tanzania, and Uganda. While their strength stems from the existence of infrastructure (0.615), inadequate economic impact (0.235) undermines logistics governance efforts in many of these countries. Moreover, they show a functional gap in terms of rail (.377), road (0.400), and river infrastructure (0.405). As regards the PI implementation, under Kenya's and Nigeria's leadership these economies exhibit a moderately satisfactory level (Level 4 cluster).

At the next, third, level is a second large group of approximately 16 countries ranging from Mauritania to Zimbabwe. These countries are closely bunched in terms of their overall evaluation score, but have widely differing strengths and weaknesses. Clearly, high LPI and LSCI alone do not guarantee readiness for the PI initiative (e.g. Malawi: LPI, 0.562; LSCI, Global). They resemble the previous group of countries for their strengths and weakness, with a less satisfactory level of economic impact (0.148) to which are grafted problems of social (0.446) and environmental (0.359) order which the logistics do not help to solve. Apart from telecoms (0.392), the sector which is the highest but not the best that displays a moderately satisfactory performance, all the other sectors in this cluster show notorious functional deficiencies. Nevertheless, the weakest sector in this cluster is the road sector (0.271). With Zambia as cluster leader, Angola, Cameroon, Congo, Djibouti, DR Congo, Gabon, Gambia, Libya, Malawi, Mali, Mauritania, North 
Sudan, Sierra Leone, Togo, and Zimbabwe exhibit together moderately unsatisfactory levels (Level 3 cluster) for the envisioned project.

Finally, a bottom tier of eleven remaining countries, ranging from Guinea Bissau to Lesotho substantially register Africa's lowest level of readiness for the PI vision. This cluster includes six landlocked countries-Niger, Chad, South Sudan, Central African Republic, Swaziland, and Lesotho-and also has low logistics activities resulting in generalized low impact. But some of them are much more highly ranked on infrastructure existence (0.279). Generally, the sectors are at best unsatisfactory as far as telecom is concerned (0.215), and at worst poor in the railways (0.110). Apart from the fact that some infrastructure exists, other indicators display red. The PI readiness evaluation provides evidence that an extreme dysfunctional state (economic impact, 0.125) and poverty as well as poor social performance often go hand-in-hand (Central African Republic). Moreover, all the evidence suggests that it is in African countries emerging from conflict that the problem of youth unemployment is most pressing. Guinea, Guinea Bissau, Liberia, Eritrea, Somalia, and the earlier cited landlocked countries belong to Level 2 cluster dark red countries, showing an unsatisfactory level of readiness as regards the PI implementation.

Among regions, North, South, and West Africa are the best performing regions on overall readiness for PI. East and Central Africa are the worst performers.

To evaluate the sectors, we relied on three international external indicators collected through researching specialized institutions: LSCI, LPI and Doing Business. According to our analysis, a good score in the LSCI does not always guarantee a good degree of PI readiness. In contrast, the levels of the LPI and that of Doing Business tend to match up with a better PI score. We will discuss all these points in the following section.

In addition to the clusters analyzed above, countries are also classified according to the following geographical zones: the regions, the Sahelian region band, landlocked and coastal countries. There are five regions grouped according to their different logistics performance, namely North Africa, Southern Africa, East Africa, West Africa, and Central Africa. Northern Africa, which is dominated by the countries in the fifth cluster, boasts of strong communications sectors and infrastructure, but is weak in its environmental impact and river system. Meanwhile, in Southern Africa, dominated by the countries in the fourth cluster, infrastructure and the communications sectors are strong, like in North Africa. But there are deficiencies in the railway system. Countries in the fourth cluster dominate in East Africa. They are similar in strength to the other regions already mentioned. They have a particularly weak railway system, and are generally weak in Doing Business. Concerning West and Central Africa, the trend is in cluster 3; good performance is in Doing Business. Maritime is to Central Africa what telecom is to West Africa. Railway is the relatively weakest of the sectors.

Landlocked countries dominate the second cluster. They are strong in telecommunications and weak in economic impact and the railway system. Coastal countries dominate the third cluster. Their strength is in telecommunications while their weaknesses are in the railway system and the river. We researched 34 out of the 38 coastal countries in Africa (CIA, 2013) and the three major hubs (Hub 
Tanger, Port Said Hub, and Durban Hub). Countries that have large coastal land mass include Madagascar, Somalia, South Africa, Mozambique, Egypt, Eritrea, Morocco, Libya, Angola and Namibia. What is common to a majority of these countries is the lack of consolidation by multipronged operators that integrate rails, road, and sea. According to LPI and LSCI, these countries are different in that they do not have the same coastal land mass and the same degree of development in logistics. Nevertheless, in our results, maritime exchanges, although weak, played a predominant role in the regions of Central Africa (0.328), and Southern Africa $(0.458)$, and the $4^{\text {th }}$ and $5^{\text {th }}$ clusters with the values of 0.487 and 0.377 respectively. As African economies become more open, the hubs would then constitute a factor in regional and international integration, a source of corresponding increase in the demands for transportation.

Table 5. Region-based results of Africa's readiness for PI assessment.

\begin{tabular}{|c|c|c|c|}
\hline $\begin{array}{l}\text { Regions } \\
\text { (\# of countries) }\end{array}$ & $\begin{array}{l}\text { Dominant color } \\
\text { (or Cluster, \% of countries within } \\
\text { region) }\end{array}$ & $\begin{array}{l}\text { Indicator } \\
\text { observation } \\
\text { (key results) }\end{array}$ & $\begin{array}{l}\text { Sector } \\
\text { observation } \\
\text { (main facts) }\end{array}$ \\
\hline $\begin{array}{l}\text { North Africa } \\
\text { (5 countries) }\end{array}$ & $\begin{array}{l}\text { Cluster } 5 \text { (2/5, 40\%) } \\
\text { (Egypt, Tunisia) }\end{array}$ & $\begin{array}{l}\text { S: Existence (.580) } \\
\text { W: Environmental } \\
\text { impact }(.379)\end{array}$ & $\begin{array}{l}\text { S :Telecoms (.525) } \\
\text { W: River (.427) }\end{array}$ \\
\hline $\begin{array}{l}\text { Southern Africa } \\
\text { (12 countries) }\end{array}$ & $\begin{array}{l}\text { Cluster } 3 \text { (4/12, 33\%) } \\
\text { (Madagascar, Mozambique, } \\
\text { Namibia, Zambia) }\end{array}$ & $\begin{array}{l}\text { S: Existence }(.532) \\
\mathrm{W}: \text { Use }(.335)\end{array}$ & $\begin{array}{l}\text { S :Telecoms (.443) } \\
\text { W: Rail (.358) }\end{array}$ \\
\hline $\begin{array}{l}\text { East } \text { Africa } \\
\text { (11 countries) }\end{array}$ & $\begin{array}{l}\text { Cluster } 4 \text { (4/11, 36\%) } \\
\text { (Ethiopia, Kenya, Tanzania, Uganda) }\end{array}$ & $\begin{array}{l}\text { S: Existence (.495) } \\
\text { W: Use (.267) }\end{array}$ & $\begin{array}{l}\text { S :Telecoms (.392) } \\
\text { W: Sea }(.307)\end{array}$ \\
\hline $\begin{array}{l}\text { West Africa } \\
\text { (15 countries) }\end{array}$ & $\begin{array}{l}\text { Cluster } 3 \text { (5/15, 33\%) } \\
\text { (Gambia, Mali, Mauritania, Sierra } \\
\text { Leone, Togo) }\end{array}$ & $\begin{array}{l}\text { S: Existence }(.504) \\
\text { W: Doing Business } \\
(.170)\end{array}$ & $\begin{array}{l}\text { S :Telecoms (.375) } \\
\text { W: Rail (.290) }\end{array}$ \\
\hline $\begin{array}{l}\text { Central Africa } \\
\text { ( } 7 \text { countries) }\end{array}$ & $\begin{array}{l}\text { Cluster } 3(3 / 7,43 \%) \\
\text { (Cameroon, Congo DR, Congo) }\end{array}$ & $\begin{array}{l}\text { S: Existence }(.470) \\
\text { W: Doing Business } \\
(.080)\end{array}$ & $\begin{array}{l}\text { S :Sea }(.328) \\
\text { W: Rail }(.247)\end{array}$ \\
\hline $\begin{array}{l}\text { Sahelian band } \\
\text { (12 countries) }\end{array}$ & $\begin{array}{l}\text { Cluster } 3(4 / 12,33 \%) \\
\text { Cluster } 2(4 / 12,33 \%) \\
\text { (Mali, Mauritania, Djibouti, Sudan N) } \\
\text { (Niger, Chad, Eritrea, Somalia) }\end{array}$ & $\begin{array}{l}\text { S: Existence (.475) } \\
\text { W: Economic imp. } \\
(.137)\end{array}$ & $\begin{array}{l}\text { S: Telecom }(.360) \\
\text { W: Rail }(.267)\end{array}$ \\
\hline $\begin{array}{l}\text { Landlocked } \\
\text { countries } \\
\text { (16 countries) }\end{array}$ & $\begin{array}{l}\text { Cluster } 2(6 / 16,37 \%) \\
\text { Cluster } 3(4 / 16,25 \%)\end{array}$ & $\begin{array}{l}\text { S: Existence }(.475) \\
\text { W: Economic imp } \\
(.281)\end{array}$ & $\begin{array}{l}\text { S: Telecom (.394) } \\
\text { W: Rail }(.311)\end{array}$ \\
\hline $\begin{array}{l}\text { Coastal } \\
\text { countries } \\
(34 \text { countries })\end{array}$ & $\begin{array}{l}\text { Cluster } 3(12 / 34,35 \%) \\
\text { Cluster } 4(10 / 34,29 \%)\end{array}$ & $\begin{array}{l}\text { S: Existence }(.545) \\
\mathrm{W}: \text { Use }(.257)\end{array}$ & $\begin{array}{l}\text { S: Telecom (.404) } \\
\text { W: Rail }(.331)\end{array}$ \\
\hline $\begin{array}{l}\text { Africa } \\
\text { (50 countries - } \\
5 \text { regions) }\end{array}$ & $\begin{array}{l}\text { North (Cluster 5, 3/5), West (Cluster } \\
3,5 / 15) \text {, Central (Cluster 3, 3/7), } \\
\text { East (Cluster 4, 4/11), South (Cluster } \\
3,4 / 12 \text { ) }\end{array}$ & $\begin{array}{l}\text { S: Social impact } \\
(.429) \\
\text { W: Use }(.283)\end{array}$ & $\begin{array}{l}\text { S: Telecom (.409) } \\
\text { W: Rail (.332) }\end{array}$ \\
\hline $\begin{array}{l}\text { Africa } \\
\text { (50 countries - } \\
5 \text { clusters) }\end{array}$ & $\begin{array}{l}\text { Cluster } 3(16 / 50,32 \%), \text { Cluster } 4 \\
(13 / 50,26 \%), \text { Cluster } 5(8 / 50,16 \%) \text {, } \\
\text { Cluster } 2(11 / 50,22 \%)\end{array}$ & $\begin{array}{l}\text { S: Existence (.539) } \\
\text { W: Environmental } \\
\text { impact }(.343)\end{array}$ & $\begin{array}{l}\text { S: Telecom (.449) } \\
\text { W: Rail }(.372)\end{array}$ \\
\hline
\end{tabular}

Source: Own investigations / Legend (S: Strength; W: Weakness) 


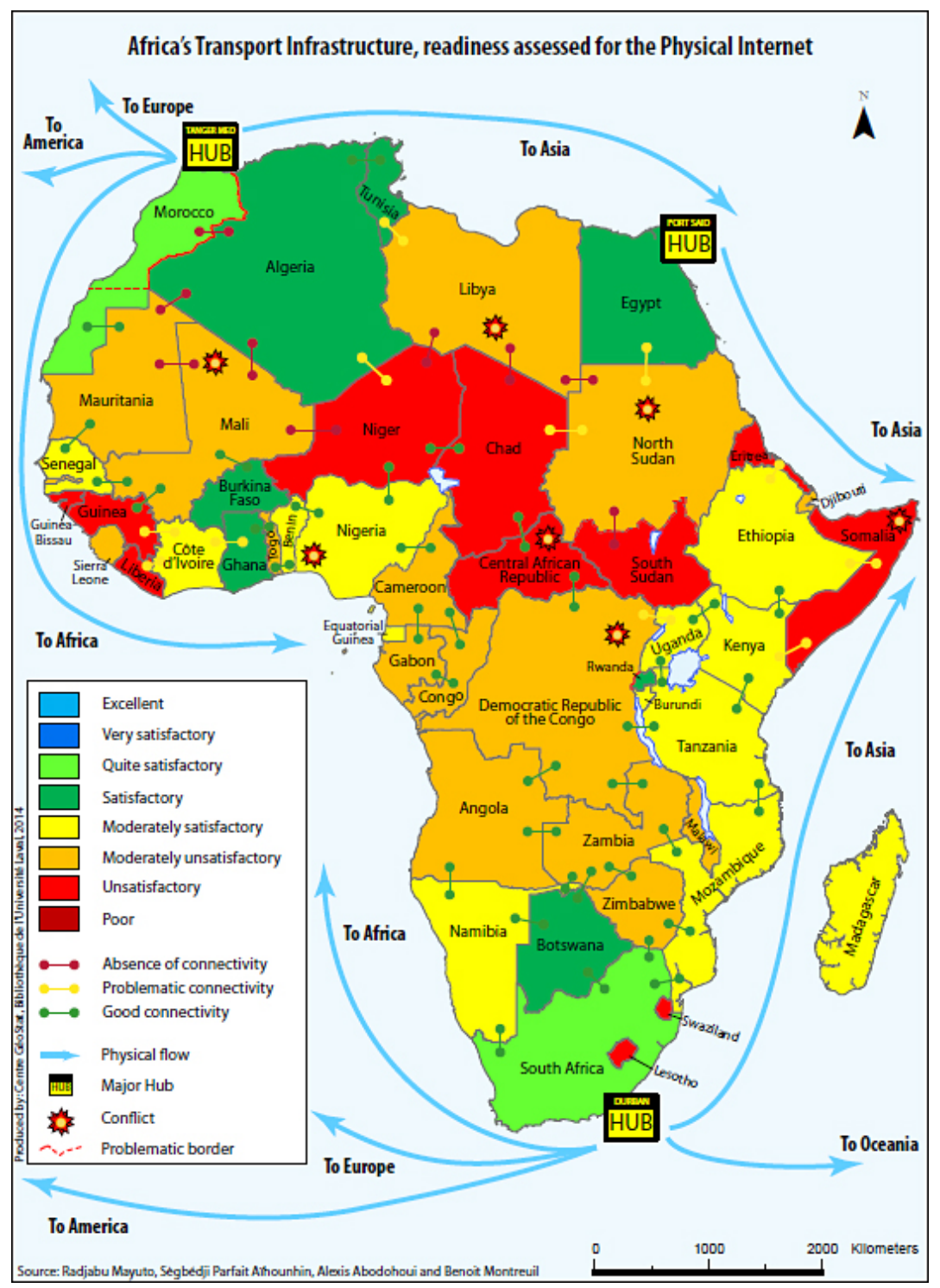

Figure 3. Mapping the assessment of readiness for PI in Africa.

\section{Discussion}

The analysis of the results we presented enable us to demarcate the major tendencies in the clusters set according to levels represented by colors (integral logistics performance). We take the regional dimension into consideration in discussing the results. Since it is more pertinent to capture the continent as a whole through its regional configuration than through its clusters of logistics performance, 
this approach has the added advantage of leading to an answer to our initial questions: What about the logistics infrastructure? Could the continent gain from being a part of the Physical Internet? Could it instill further economic growth while contributing to environmental and social sustainability in Africa, which presents itself as the continent of the future? Among all African countries, which ones are readier than the others to contribute to Physical Internet inquiry and implementation? This is why many points were taken into account in this section. The weaknesses and strengths of the continent concerning the magnitude of the logistics activities and its impacts on society would help one to make the appropriate diagnosis. This helps to put a critical emphasis on the question of the index that is normally used to evaluate the logistics performance of countries. This would in turn lead to taking some major corrective measures. Finally, we will analyze all of Africa according to how the continent is understood today, and then make a long-term prognosis.

\subsection{Strengths and Weaknesses of Logistic Performance on the Continent}

Two strong points and three weak points support a relatively precarious diagnosis. On the one hand, the performance (magnitude) of the logistic activities on the continent is based on the presence of logistics infrastructure (1) in all the states of Africa. The most remarkable presence is found in the maritime, aerial and telecommunications sectors. Of all the logistics sectors, telecom (2) is the one that is currently making the strongest social impact. This trend is found in all the geographical categories - the Sahel region, the landlocked countries, the coastal countries. On the other hand, the weakest measures are comprised mostly of the use of transport infrastructure, (3) and economic impact (4), followed closely by connectivity (5). These are found in nearly all the sectors. Even though the environmental situation is not ideal, it is not as bad as that of connectivity. This is because logistics performance could become worse with deficient connectivity.

The presence of infrastructure varies according to geographical location (landlocked vs. coastal countries) and the level of the economic development of a country. The coastal position is an advantage in terms of added value (Ndulu, 2006) such as those displayed in the LSCI (UNCTAD) index. In spite of the fact that international transit is the extension of the operational chain of national transit and vice versa (Arvis et al., 2014; World Bank, 2008), this index incorporates only maritime commerce. It does not include overall connectivity. Even the LPI that is supposed to measure the logistics performance of a country (World Bank) does not take into account the connectivity of domestic routes of transportation (Wilmsmeier \& Hoffmann, 2008). These two indexes certainly indicate the level of performance but without netting the cumulative effect of an overall connectivity. The data from the intra and intermodal network is absent in the calculation of indexes. Since the network connections do not take into account this reality and its contribution as proposed in the concept of the Physical Internet (see the theoretical section), the performance assessed by these indexes are as a result partial. The concept of the Physical Internet corrects this aspect by integrating into its construction not only the causes of the magnitude of the logistics activities with a component dedicated to overall connectivity (global and domestic), but extends its significance to the impacts resulting from this usage as a whole. Because the Physical Internet reconfigures the logistics performance by integrating the totality of the social facets, the performance measured under this scale is a total performance and therefore ideal. 
Moreover, an ideal interconnectivity would take into account sectoral and intersectoral branches of the transportation infrastructure that optimize logistics performance through a multimodal reach (from production to distribution and exportation, urban/rural-rural/urban).

Thus, being derived from both a connectivity and an exploitation that are weak, logistics performance has only a minor influence on Africa's economic life. We gauged the economic impact using Doing Business 2014. In fact, the continental average of the regions estimated at .299 shows that in spite of the presence of a logistics infrastructure, African countries suffer from a dearth of business climate. The highest level in this indicator was reached by northern (.562, level 5) followed by southern Africa (.395, level 4) while central Africa occupies the ground level (.080, level 1$)$. When a country has a low-level infrastructure, marked low usage as well, that could lead to a mediocre Doing Business ranking with a very minor to almost non-existent social and environmental impact. This is the case of the red countries on the map (level 2). This tendency also affects countries on level 3, the majority (5/16) of them found in the West African region. The weakness of Doing Business is very evident in all the regions, but more prominent in the West (.170) and in Central (.080) Africa.

On the one hand, the results point to the major problem of socio-economic impact, on the other hand, the use of infrastructure and their connectivity also hinders logistics performance on the continent. All things being equal, North Africa is the region where this is most rampant. Although this region reigns in the general readiness plan (.500 versus .388), this region that is endowed with 2 of the 3 main hubs in Africa does not have connectivity worthy of its position (.441 versus .351) compared to southern Africa which follows it. Its environmental impact is moderately satisfactory (.379, level 4).

\subsection{Focus on Land Transport}

The difference between landlocked and coastal countries in Africa is still significant but not very clear. Coastal countries, with the exception of South Africa, also experience such serious problems as port congestion, which reverberate to the countries in the Interior. (Limao \& Venables, 2001; World Bank, 2008.)

In East Africa, roads constitute the densest transportation network. Truck based transportation is developed between regional cities. The coastal cities of Dar es Salaam (Tanzania) and Mombasa (Kenya) are home not only to seaports but also to international airports. Despite being landlocked, Uganda has a good roads network that makes it a hub between Sudan, Kenya, Congo, and neighboring Rwanda. Similarly, Lake Victoria is a relay with Tanzania.

Another example is furnished by the red countries (11 in Cluster 2); their overall score is inferior or equal to .218, they are both coastal (5) and landlocked (6). For the most part they are located at the Sahel region. The analysis of the collected data shows that in these countries, it is the whole of logistics infrastructure that is deficient [Logistics Performance Index (LPI), .221; Doing Business (DB), .137]. 
In addition to the problem of dilapidated rail and road infrastructure, another important issue is the rapid and progressive desertification (Yahmed, Houstin, Pitte, \& Cartographie, 2011) that threatens the opening of areas already affected by isolation and long periods of famine.

The succession of dry seasons in this part of the continent coupled with the rising prices of essential commodities, and all-out conflict, has been and still is a problematic situation for the people of this region. This has exacerbated the flow of goods and services, and the difficulty in reaching populations in need. This situation has also left millions of people in Kenya, Somalia, Ethiopia and Djibouti in a humanitarian crisis, the consequences of which are still visible today. According to the UN, at least 13.3 million people, including children, are malnourished and exposed to disease and violence (CIDA, 2013).

Moreover, they are countries that have gone through many decades of all kinds of instability. Many of them are still going through it today: the socio-sanitary crisis in the West (Ebola in Guinea and Liberia), socio-political and religious tensions from east to west (Niger, Nigeria, Central African Republic, Sudan, Somalia), etc. These situations are detrimental to the effective implementation of PI in these countries.

From a connectivity perspective between different countries in the region, for example Ethiopia with Addis Ababa (by road or flight) and Somalia with Mogadishu (road and air) could provide a shortcut access route to Asia by exploiting Djibouti and Mogadishu as important hubs (Yahmed et al., 2011).Unfortunately, terrorist acts perpetrated in this part of the continent do not allow Djibouti, with its commercial port and oil terminal, to play its role in the amount of transit traffic through the International Autonomous Port, Ethiopian and Djibouti International airports, and the railway to Addis Ababa (Yahmed et al., 2011).

\subsection{Focus on Maritime Transport}

In the effort of bringing the African continent into the PI initiative, three types of geographic entities should be given consideration: countries, regions, and continents. These entities are intimately intertwined so that the operation of logistics within each entity, the operation of logistics between entities, as well as the connection of Africa to world trade are cross-cutting concerns whose mechanisms should be defined and established modularly. This involves grouping functions interconnected by interfaces, which will be local (central and peripheral) and/or service interconnection with overseas modules. These functional connections or interfaces are sorely lacking sectoral level transport, so that the gap within countries and regions, and even the continent, and between urban (centers of manufacturing, consumption of services) and rural regions (agricultural producers) has deepened.

Internally, communication networks exist in several countries, but the continent suffers from logistical obsolescence and inefficient interconnection between sectors. Aided by global donor funds (such as China, the European Union, multilateral development banks, and regional development banks), different economic communities and national governments have engaged in work to resolve this national issue at the regional level (ICA, 2014). In addition, the 2013-2022 integration strategy toward the transformation of Africa by the African Development Bank includes chapters on transportation and telecommunications (BAD, 2013). The 
World Bank's Transport Strategy objective is to help partner countries to establish the governance, strategies, policies, and services that will deliver transport for development in a way that is economically, financially, environmentally, and socially sustainable (World Bank, 2013).

Externally, Africa's main cargo ports are pivotal for it to do business in world trade. Mundy and Penfold (2008) found in Sub-Saharan Africa that the port of Durban and Port Said in Egypt annually handle nearly 9 million tons of cargo through its transiting freighters. The container ports Tanger Med, Port Said, and Durban handle close to 3.5 million TEUs (Institute of Shipping Economics and Statistics, 2010). These ports provide access to major shipping routes as follows:

- Tangier Med by the Atlantic Ocean to northern Europe, North America, South America, West Africa and South Africa to Asia via Port Said

- Port Said, to Asia and to East Africa, also to Tanger Med

- Durban by the Indian Ocean to Africa, Asia, Oceania; by the Atlantic Ocean to West Africa, South America, North Africa and Europe

These three ports are not only connected to major extra-continental shipping routes, they also allow intra-continental connectivity by road, air, and/or rail. In this sense, they are major hubs and are recognized internationally as a symbol of regional integration in African trade.

Southern Africa has one of the three largest hubs of the continent and serves regional, interregional and international (transcontinental) transportation needs. South Africa is a green-ranked country due to the existence, use and connectivity of logistics infrastructure. It offers many more opportunities for cross and internal connectivity than the other two (Morocco with Tangier Med, Egypt with Port Said). South Africa, Botswana, Tanzania, Rwanda, Burundi, Angola, Mozambique, Namibia, Chad, Sudan, Kenya, Nigeria, Djibouti, Senegal, among others, are the main countries related to that program. In addition, the ongoing construction of a railway line between Kinshasa and the river port of Ilebo (Kasai, DRC) will link the whole of Africa to the South African port of Durban.

With the Physical Internet, logistics and transportation are not only multimodal. It is also about intermodal and technological efficiency and reliability that engages and interconnects an entire social community of operators, enablers, and users (economic, social, environmental, governmental, and civil society). In addition, the rational management and implementation of PI-enabled interconnected logistics foster potential order-of-magnitude improvements in environmental, social, and economic efficiency and sustainability.

\subsection{Africa, from Short to Long Run}

Moreover, although the results obtained in this study open the way to rather mixed prospects, the contributions are of two orders. From a theoretical point of view, content analysis is used to conceptualize and evaluate the Physical Internet. From the practical point of view, the realized African geographical map accounts for the applicability of the notion of the Physical Internet. This map can be used as a 
decision-making tool by governmental bodies and agencies involved in the development of transport infrastructure on the continent.

\subsection{Addressing the Missing Piece of the Study}

A limitation of this assessment is that it analyzes only one dimension of performance, which is an inherent limitation of any cross-sectional analysis. Therefore, a subsequent analysis should investigate how skills development measures vary across countries on the continent. Additionally, future research should address this issue in light of governance reforms.

Missing from the study is an assessment of capacity building across the continent (countries, regions), as has been done on the transport infrastructure itself. Unfortunately, the lack of related data did not allow us to undertake such an exercise. Such an assessment would have served to gauge the human capital held (supply side) by a country in relation to the needs of the Physical Internet (demand side).

In the following section we consider the results analyzed and discussed above, as well as the limitations previously mentioned, to conduct a deep reflection devoted to the capacity building strategies accompanying the development of the Physical Internet in Africa.

\section{Toward strategies of capacity building in transport infrastructure and Physical Internet}

To the question of what strategies African countries should employ if they aspire to join the Physical Internet initiative, the response is unfortunately not a straightforward one. Strategic reflection/thinking is conditioned both by the thought that inspires it but also by the reality that concretizes it. In this respect, this will depend on which national authorities are interested and what level of readiness the country has reached as assessed by our study (obtained score or cluster). Good brainstorming will aim to include infrastructure and competence issues in country and regional strategies, as well as partnerships with interested countries to promote infrastructure and development and to make infrastructure a positive force for development. Strategic reflection is not now needed for the future, if economies are to continue to have the same levels of logistics efficiency. Strategies formulated in this section are proposed for the short, medium and long term. Strategies summarized in the following tables are derived from the results obtained in this study.

\subsection{The response is implicit in the charts and tables}

From the foregoing, can we say that Africa is ready to welcome the project, establish it, and take full advantage of it? In order to answer this all-encompassing question correctly, it would be wise to consider a regional perspective. Thus, from Table 6 , one observes that 10 of the continent's countries $(20 \%)$ would be ready with a few adjustments. The North, home to four of these countries, would meet the challenges of interconnecting the Maghreb, not only through the Mediterranean Sea, 
but it is also vital that these countries (Morocco, Algeria, Tunisia, and Egypt) find alternative land routes for intra and interregional commercial exchanges. The West (Ghana, Burkina Faso) would have to help in unlocking the landlocked countries close to the Sahara, but unfortunately the intractable issue of security in this region remains a source of constant concern (when, where, what would spark the conflict?). In the south where the weakness is quite visible in the use of infrastructure and its socio-economic and environmental impact, efforts must be channeled into a vision of regionalization to which one has already been committed and for which Botswana and South Africa act as models.

In sum, the diagnosis of a relative instability of the infrastructure results mainly from its use, which remains affected by unsatisfactory connectivity: to be sure, the present infrastructure needs some readjustment, but mostly by a government with a targeted and results-oriented program, with which Africa is capable of meeting the challenge thanks to the kinds of possibilities we have discussed here.

Table 6. Countries distribution by clusters and regions.

\begin{tabular}{|c|c|c|c|c|c|c|c|c|}
\hline Countries & Cluster $\mathbf{6}$ & Cluster $\mathbf{5}$ & Cluster $\mathbf{4}$ & Cluster 3 & Cluster 2 & Cluster 1 & $\begin{array}{c}\text { Total Africa/ } \\
\text { Region }\end{array}$ \\
\hline North Africa & 1 & 3 & & 1 & & & 5 & $10 \%$ \\
\hline $\begin{array}{c}\text { West Africa } \\
\text { Central Africa }\end{array}$ & 2 & 4 & 5 & 4 & & 15 & $30 \%$ \\
\hline $\begin{array}{c}\text { East Africa } \\
\text { Southern } \\
\text { Africa }\end{array}$ & 1 & 2 & 3 & 4 & 2 & & 7 & $14 \%$ \\
\hline $\begin{array}{c}\text { Total Africa/ } \\
\text { Cluster }\end{array}$ & 2 & 8 & 13 & 16 & 11 & 0 & 50 & $100 \%$ \\
\hline
\end{tabular}

Source: Own investigations

\subsection{Remedying the pan-African situation requires a vision, a plan and actions (filling some of the gaps in implementing the PI vision)}

The necessary remedy requires a long-term vision for the whole of Africa so that infrastructure can play its full role in stimulating and supporting economic and social emancipation without demeaning environmental considerations. To do this, to work for the future of the continent, one has to stick to the vision of the Physical Internet for its benefits as regards the future of infrastructure in general and for people in particular. Thus, in working to reduce or remove the weaknesses found and discussed above, the overriding concern should be to establish/reestablish the balance between logistics activities and their impacts as objectives and not as incidental occurrences. In this way, three vistas support this proposal. First, remove infrastructure from its colonialist schema; this would mean (a) building logistics bases while taking into account not only foreign needs but also local and regional usefulness - the example of the construction of African railway lines is remarkable and regrettable (gauge differences), (b) taking into consideration the 'intelligent' sectoral and inter-sectoral connections, and, (c) doing the necessary follow-up and control for proactive performance management: to no longer have to wait for the publication of the annual classification of logistics performance index before acting or reacting. 
Second, bring in a government capable of solving the ringing weakness of Doing Business. The reason for this weakness is the inefficient use of infrastructure. Taking the preceding point into consideration would lead to the expected, or at least desirable results, because it was planned. Since the continent is in a period of almost generalized construction, it is a good sign of the improvements that are going to be felt in the coming years. Many countries are embracing reforms. In fact, according to the Doing Business report 2015, Benin, Togo, Cote d'Ivoire, Senegal, and the Democratic Republic of Congo are among the countries that have undertaken the greatest number of reforms that would allow them to improve their business environment. However, if these reforms are not well thought out, the negative consequences would be perceived too late to be easily corrected, given the enormous costs committed or to be committed. Improving the infrastructure, managing the transit corridors as regional public goods through international cooperation, and establishing alternate transit routes to reduce the monopoly power of any given coastal economy to improve the trade outcomes for landlocked economies are three main policy implications (Grigoriou, 2007; Lahiri \& Masjidi, 2012).

Third, some weaknesses are the result of a chain of causes (variable and invariable) outside the infrastructural context. The three situations that illustrate this point require a specific treatment. (a) For instance, geographical enclosure would make one think of a natural isolation of countries with no coastal areas. Still, that a country is landlocked does not mean it has an enclosed economy; and the phenomenon that one observes in all of the regions of Africa, except North Africa, does not always explain the very poor scores obtained by a country. Even if being landlocked comes with extra trading costs, the density and quality of internal infrastructure are also determining factors of any country's trade costs, though perhaps more important in terms of trade policy (Carrere \& Grigoriou, 2008). Limao and Venables (2001) emphasized that distance explains only $10 \%$ of changes in transport costs. Poor road infrastructure represents $40 \%$ of the transport costs predicted for coastal countries and $60 \%$ for landlocked countries. However, some landlocked countries perform better at the expense of countries they use as transit points (Botswana vs. Namibia, Burkina Faso vs. Cote d'Ivoire/Togo/Benin, Rwanda vs. Tanzania). Lessons from Lahiri and Masjidi (2012) suggest a robust explication in terms of the following corollaries.

Corollary 1: A landlocked economy that is centrally located and can offer cheap direct land routes to other economies of the region has a stronger bargaining power and only has to offer lower concessions to its coastal neighbor in order to extract a similar reduction in obstruction to ocean access.

Corollary 2: A landlocked economy that has a well-developed domestic industry will be able to bargain for a greater reduction in obstruction to ocean access as the coastal neighbor has a vested interest in participating in the domestic industry of the landlocked economy. (Lahiri \& Masjidi, 2012: 517).

The competitiveness of a port depends not only on its infrastructure and its services, it also lays in the quality and fluidity of land transport networks that serve mostly regional interconnection routes (Atlas de l'Afrique, 2009). Maritime and transit transport is not only a vital activity for international trade; it has in itself an 
international character as its modus operandi. Opportunities, problems and policy issues related to maritime and transit transport transcend national boundaries and are best addressed at the ECOWAS, UEMOA, CEMAC regional and international integration levels (Abodohoui, da-Silva, Tossou, \& Su, 2014; Akanni-Honvo, 2003).

Countries in a given maritime region share common problems of demand and supply of maritime transport services, and of security, safety, and pollution of marine waters. Therefore, the maritime area lends itself to sectoral integration in this range. Shared concerns often pointing to concerted resolutions include promoting maritime security and environmental protection by the elaboration of effective emergency plans for the prevention and the fight against pollution; strengthening the efficiency of the maritime administrations; and implementing control measures of the flag state and the control of ships by the port state.

Table 7 contrasts four key characteristics of the Physical Internet with the current logistics system as pertinent to Africa. This remains at a qualitative level as there is a huge lack of data supporting a quantitative assessment. In this context, a preliminary study estimating the economic, environmental and societal costs of current logistics on the continent would be highly pertinent and beneficial.

Table 7. Key comparisons of current vs. Physical Internet logistics systems as pertinent to Africa.

\begin{tabular}{|l|l|l|}
\hline & Before PI & After PI \\
\hline Intermodal logistics & Weak & High \\
Asset utilization/exploitation & Personal & Public \\
$\begin{array}{l}\text { Performance of critical } \\
\text { parameters* }\end{array}$ & Isolated, private, sensitive & Synchronic, collective, superior \\
\hline
\end{tabular}

* Speed, service levels, reliability, safety and security (Source: created by the authors).

The African PI implementation would gain from adopting the common objectives of the Regional Economic Communities (RECs) and of the International Physical Internet Initiative. Growing the PI implementation in two major Free Economic Zones (FEZ) in Africa should be considered: (1) the South East FEZ group including COMESA, SADC, EAC and IGAD along South Africa, and (2) the Northwest Centre FZE group including ECOWAS, CEN-SAD, ECCAS and AMU along the Morocco-Mauritania-Senegal-DRC axis. The full logistic interconnectivity of the continent would then be based on the East-Central and South-Central junction. From another perspective, all African countries should independently and collectively address how the PI can help them develop sustainably by building a pragmatic roadmap from their current logistics system to an interconnected logistics system, providing an opportunity to interconnect by priority the readiest regions to build success and momentum and to pull up the overall continent.

Beyond all these considerations, along with the infrastructure upgrades, transport policies should dispose of the regulatory framework of appropriate transport infrastructure and skills required (by private and public stakeholders) in this sector. They will then be able to provide the basis for efficient, sustainable, safe and secure freight transport and mobility and will ensure a level playing field between all industries involved. 
The concept of competence in the management area makes use of the capacities of an individual to perform a function or perform a task in accordance with required standards (Klarsfeld, 2000; Delamare, Le Deist \& Winterton, 2005). Developing it in an individual is assumed to raise the knowledge level and ability of this person in order to enable him to operate safely, carrying out the activities entrusted to him/her or in which he/she is engaged.

As part of the development of Physical Internet in Africa, skills development, sine qua non-condition, is an essential basis for mastering growth interconnectivity of transport infrastructure, the intermodal development of which goes through the progressive transfer and continuity of knowledge.

Knowledge transfer should mean here, controlled and structured development of research centers and training facilities geared towards sustainable and equitable development in Africa. This also implies a reorientation of the African education system that takes into account local realities (oriented training needs in transportation infrastructure) in both the short, medium and long-term policies as well as development and growth strategies.

Such an approach should, first of all, consider contributions from external sources (external inputs) in the form of skills, advice, proprietary technologies, and cooperation networks. Indeed, the knowledge base, which provides the solutions to problems that the enterprise/country cannot resolve from its internal resources, is an essential part of the framework conditions.

Borrowing from the European Commission view adopted in their Innovation Policy, focusing on "entrepreneurial innovation" (European Commission, 2003), we argue that three main "dimensions" to the policies appear to impact on these components of the innovation area. Firstly, the "policy governance" dimension: policies influencing the innovation capabilities of enterprises are made at local, national, regional, continental, or even global levels. While most innovation policy is defined at national and regional levels, it is the role of such structures to enhance efficiency by offering appropriate co-ordination mechanisms at the regional level. The communication makes concrete proposals for how to turn Africa's diversity into strength. Secondly, the sector-specific dimension: many factors affecting innovation are common to all industrial sectors, but some sectors, such as information and communication technologies, the waterways and railways industries, for example, have highly specific characteristics and therefore require specific policy responses. The need for a more sector-specific focus is also part of this new approach to industrial policy. Thirdly, interaction with other policy areas: innovation policy must often be implemented via other policies. Innovation must increasingly be embedded in many policy areas. Competition policy, as well as fiscal, labour, environmental, and trade policies are obvious candidates for establishing close co-ordination mechanisms; the energy sector as well. In this sense, the development of infrastructure, from transport links to water and sanitation facilities, is key to releasing populations from poverty and unleashing economic potential. But the infrastructure gap remains huge. To bridge this gap, now more than ever the public and private sectors need to work together (African Union, 2016). The communication suggests proactive policy screening and high-level co-ordination as streamlining mechanisms. 


\subsection{Emergence of strategies}

\subsubsection{Schematizing strategic thinking: governance and transport}

From the results obtained in our study on the Physical Internet and discussed in the preceding paragraphs, four key strategic underlying challenges that emerge are of great interest:

- On the one hand, a lack of logistical performance even though it is recognized as important;

- On the other hand, there are considerable difficulties of economies to achieve infrastructure across all sectors for the many reasons we intimated above;

In the same vein, in order to build the real foundations for the development of the Physical Internet on the continent, it would be necessary to strengthen capacities in the infrastructure field of transport; which would be an unstoppable asset. But, on this issue it must be noted that:

- There is, on the one hand, an acknowledged lack of capacity building even though it is recognized as important; and

- On the other hand, there are difficulties in building human resource capacity at the same time.

All these observations are centralized to motivate strategic intent in relation to strategic choices that leaders and rulers must make to undertake sustainable and economically responsible changes, in doing so endorsing the importance of the governance and transport critical factors. Those observations appear as strategic pillars that govern the national choice. This choice has the following options which are: undertaking oneself or "Doing Alone", entrusting to others or "Make Doing", cooperating with others or "Doing With", "Not Doing” (Su et al., 1999).

In most democracies, power had become decentralized and increasing affluence in the late twentieth century further loosened the control potential of government. Governance became a matter of organizing the interplay between the various actors in the network. The view on government changed from ruler to coordinator. Hierarchical governance was supplemented with network governance (Button et al., 2010: 178). Hence, when looking at transport, two newer forms of governance are observed: network and market. Therefore, the authorities developing infrastructure that had traditionally only been accountable to the responsible political leadership, had to open up because of the increase in network governance. Accordingly, options are: (1) Doing Alone (DA): this choice is made when the decision-maker has the means to carry out the activities/markets; (2) Make doing (MD): the decision-maker opts for this strategic choice when he does not have the necessary resources and/or the capacity to carry out the activities himself. In most cases, this option is chosen when it is recognized that expertise is external to the system being managed/governed; (3) Doing With (DW): under this option, it may be a subcontracting of the work to be carried out or a task/activity carried out in conjunction with external expertise in the objective to ensure a gradual transfer of the knowledge or competence sought; (4) Not doing (ND): This option is chosen when 
the activity is deemed unsatisfactory. In this context, one does not commit to embarking on the project.

However, we need to ensure that by doing so, each strategic governance option is selected as a result of careful study and research leading to an optimal decision. Whatever the choice, it is supposed to correct the difficulties in building infrastructure, or strengthen human resource capacities for an efficient implementation of the Physical Internet.

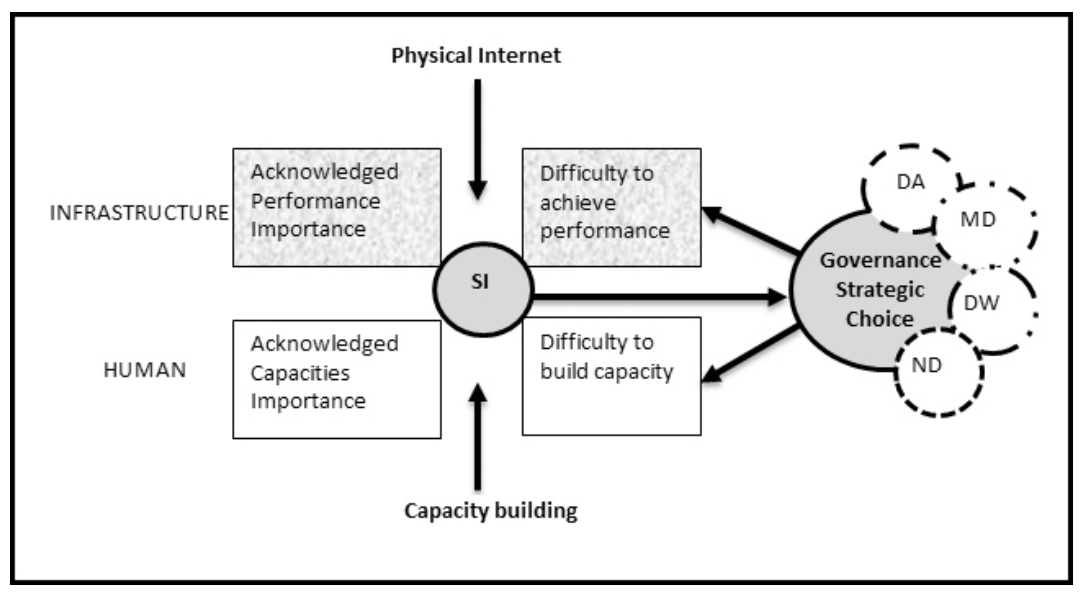

Figure 4. Schematizing strategic thinking about African transport infrastructure governance.

Legend: SI - Strategic Intent; DA - Doing Alone; MD - Make Doing; DW - Doing With; ND Not Doing.

\subsubsection{Division of capacity building labor}

When a State is considering the development of its transport infrastructure, it is faced with a series of questions relating to high-level strategic planning, such as identifying and selecting the most suitable and attractive sectors and routes (profitability) or determining the feasibility of such work. For example, "For development of rail networks, market governance has gained importance, where governments set general goals and routes but private parties [...] design, build and maintain (DBM) lines and networks, or in addition also operate (DBOM) them." (Button et al., 2010: 194).

In order to effectively implement strategic choices, leaders must respond to five strategic questions: What, Who, Why, When, and How. As regards capacity building, we draw inspiration from Burawoy (2005) in addressing and extending two main questions: Capacity building for what? Capacity building for whom? We provide answers to these essential questions applicable depending on the target audience (academic or extra academic). Table 6 below highlights the possible solutions to be taken into consideration. 
In this context, scientific research on societal problems will have to provide appropriate solutions that develop the knowledge to be acquired and the necessary norms, behaviors, and know-how for community development. It is only after this stage that professionals can develop the necessary expertise and then popularize, educate and inform the public about the optimal ways of running the community. One of the important points of these strategic reflections is how to implement the solutions resulting from this research for the well-being of the population. This is where the real strategic choices come in, which have to be coupled with the three important phases of realization of a project/activity: strategic design, operationalization, and control. At this level, the strategic design phase should be carried out with the aim of matching the infrastructural realities with respect to the Physical Internet and an obligation to develop the necessary distinctive competencies. The implementation of controls, whose purpose is to comply with the forecasts, should be done by ensuring that the standards and procedures are mastered by the professionals. That would be an advantage to the better management of the public good. Since the research and teaching of standards and procedures are the responsibility of the academic world, participation in monitoring and satisfaction surveys will have to be ensured by the public, to whom good governance is accountable. However, the thorny question of periodicity cannot be excluded from strategic options (Doing Alone, Make Doing, Doing With, Not Doing). Logically, it is part of the time horizon. However, the implementation of "when to develop skills" requires unavoidable conditions that are in the control of resources (raw materials, human and financial) and a critical mass of competent trainers. Thus, regardless of the time option chosen (short, medium or long term), only one configuration is available for capacity building: the one that makes the Physical Internet applicable to the academic world and professionals. Thus, the latter, having become familiar with the concept, will in turn inform the public during and after its advent. 
Table 8. Division of capacity building labor*- African Transport infrastructure.

\begin{tabular}{|c|c|c|c|c|c|c|}
\hline \multirow{2}{*}{\multicolumn{3}{|c|}{ For whom? }} & \multicolumn{2}{|c|}{ ACADEMIC AUDIENCE } & \multicolumn{2}{|c|}{ EXTRA-ACADEMIC AUDIENCE } \\
\hline & & & Researchers & Teachers & Professionals & Public \\
\hline \multicolumn{3}{|l|}{ What? } & Research & Teaching & $\begin{array}{l}\text { Practice } \\
\text { Public education }\end{array}$ & Participation \\
\hline \multicolumn{3}{|c|}{ For what? } & $\begin{array}{l}\text { Finding } \\
\text { solutions to } \\
\text { society's } \\
\text { problems }\end{array}$ & $\begin{array}{l}\text { Acquiring } \\
\text { knowledge, } \\
\text { know-how, } \\
\text { and } \\
\text { behaviors }\end{array}$ & $\begin{array}{l}\text { Developing } \\
\text { in-country } \\
\text { expertise } \\
\text { Raising } \\
\text { awareness }\end{array}$ & Inquiring \\
\hline \multirow{4}{*}{ How? } & \multirow{4}{*}{$\begin{array}{l}\text { Doing Alone } \\
\text { Make Doing } \\
\text { Doing With } \\
\text { Not Doing }\end{array}$} & $\begin{array}{l}\text { Conceptualizing } \\
\text { Strategic } \\
\text { knowledge }\end{array}$ & \multicolumn{2}{|c|}{$\begin{array}{l}\text { Standards and Procedures } \\
\text { Adequacy and distinctive } \\
\text { competencies }\end{array}$} & \multicolumn{2}{|c|}{ Standards and Procedures } \\
\hline & & $\begin{array}{l}\text { Operationalizing } \\
\text { Instrumental } \\
\text { knowledge } \\
\text { (focused on } \\
\text { means) }\end{array}$ & \multicolumn{4}{|c|}{$\begin{array}{l}\text { Knowledge transfer } \\
\text { (Effective, Efficient and Sustainable Communication Tools) }\end{array}$} \\
\hline & & \multirow[t]{2}{*}{$\begin{array}{l}\text { Controlling } \\
\text { Reflexive } \\
\text { knowledge } \\
\text { (focused on ends) }\end{array}$} & \multicolumn{2}{|c|}{$\begin{array}{l}\text { Acceptability of standards } \\
\text { and learning } \\
\text { Research and teaching of } \\
\text { control }\end{array}$} & \begin{tabular}{|l|} 
Audits and \\
satisfaction \\
surveys \\
(Compliance \\
with planning)
\end{tabular} & \multirow[t]{2}{*}{ Participation } \\
\hline & & & \multicolumn{3}{|c|}{ (Mastery of Standards and Procedures) } & \\
\hline \multirow{4}{*}{ When? } & \multicolumn{6}{|c|}{ Mastery of resources (raw materials, human and financial) and capacity development } \\
\hline & \multirow{3}{*}{$\begin{array}{l}\text { Doing Alone } \\
\text { Make Doing } \\
\text { Doing With } \\
\text { Not Doing }\end{array}$} & Short-term & \multicolumn{2}{|c|}{$\begin{array}{c}\text { Before PI } \\
\text { (Physical Internet) }\end{array}$} & Before PI & $\begin{array}{l}\text { Before PI } \\
\text { After PI }\end{array}$ \\
\hline & & Medium-term & \multicolumn{2}{|c|}{ Before PI } & Before PI & $\begin{array}{c}\text { Before PI } \\
\text { After PI }\end{array}$ \\
\hline & & Long-term & \multicolumn{2}{|c|}{ Before PI } & Before PI & $\begin{array}{c}\text { Before PI } \\
\text { After PI }\end{array}$ \\
\hline
\end{tabular}

*Addressing two main questions: Capacity building for What? and Capacity building for Whom? (Adapted from Burawoy, 2005). Contextualize the development of skills according to the specific needs identified.

\section{Conclusion}

The objective of this work is to assess the readiness of 54 African countries for the implementation of the Physical Internet. This study provides a unique reference to better understand logistic impediments and its unsustainability in Africa. The key findings show the strengths and weaknesses for each country, region, and the continent as a whole. The African transportation system lags behind that of the rest of the world, with a level of development still lower than other developing countries in Asia (Rodrik, 2014; UNECA, 2014). Many countries remain critical relative to national logistic competiveness. We hope that this paper would help to improve ideas towards the quality of Africa's logistics infrastructure through the support of leaders, changemakers in business, government, and civil society inspiration to action. Further studies need to build on the PI index as a logistics catalyst. Priorities for previous research include the construction of the index of PI through ongoing feedback and testing, identification of some factors for better measurement of social progress, and also factor 
analysis needs to be conducted in order to understand the relationship between the logistic situation (outcomes) and the policies of each country.

The analysis is focused on the resource levels (transportation and inventory) needed by the current supply model and by the Physical Internet in order to serve a market with a logistics policy that is efficiency-sustainability oriented. The essence of PI is to interconnect heterogeneous and independent logistics networks, and to move towards a common open logistics network (Pan et al., 2013). Accordingly, Africa's diagnosis presents 10 countries of which 2 (Morocco and South Africa) are more advanced than the 6 (Algeria, Egypt, Burkina Faso, Rwanda, and Botswana) that need a strong adjustment to be ready for PI. Moreover, zoning the continent, South Africa seems to be the region that is the most prepared for PI. Indeed, to involve Africa the project has to grow first in fertile areas and be collaboratively supported by key leaders from industry, government and academia (Montreuil, 2011). The South African region ideally embeds it.

This work has significant limitations. First, there is a scarcity of statistics on goods transportation and warehousing. The inaccessibility of these secondary data makes the quantification of Physical Internet readiness difficult. Thorough research should be continued in this direction. Secondly, the ambiguous literature requires evaluating the information conveyed with caution. Reliability cannot always be guaranteed. As a research avenue, in light of the regional divisions in Africa, it is important to dwell on the study of Physical Internet zones, allowing for a closer view of the current reality superimposed on the potential realization of this great initiative.

Research findings contributed much to the understanding of how to infuse the stagnant traditional world/African transport model with promising vision and energy. While previous research works are technically based, we aim to study the readiness of Africa for such a global logistics initiative. Measuring Physical Internet readiness is the key to advancing it. Following the Physical Internet foundations, we built a framework that enables understanding PI as an institutional vision of a holistic logistics infrastructure through a cause-consequence lens of logistics activities. As a first step, the contribution of this paper is to define the PI framework and assess the readiness for new strategies- not of replenishment but as an adjustment within a functional logistics system enabled by the PI vision, and thus to outline the potential of this kind of system. However, it is important to point out that our objective is not to define the best strategy of inventory management in the PI network, but to study the performance level of such a logistics network and to plan the implementation of the concept. Therefore, we took into account the reality of the region. Most international trade on the African continent continues to be transported by sea, and port amenities are still a crucial mode in global shipping. LPI and LSCI are determinant keys of international Maritime freight rates. These measures of port efficiency or performance indicators use different indices and techniques for assessment and analysis but might indicate that ports are very dissimilar from one African country to another. Furthermore, these different indexes do not computerize some variables such as the connectivity between African countries, geographical distance between countries, and their level of development (Wilmsmeier \& Hoffmann, 2008). All these criticisms have led us to propose, in the framework of this study, the analysis of the intra-sectoral and inter-sectoral interconnectivities at 
the domestic level, that is, the interior of the continent. All the specifics that do not incorporate the aforementioned indices.

Secondly, as noted above, through its methodology this study also paves the way for the establishment of the PI index. Thirdly, still, to fully understand the entrepreneurial process requires starting with an examination of the potential causes and consequences. This paper has shown the value of examining potential entrepreneurs in two unified conceptual entities: activities within logistics transport infrastructure, and impact development, into three organizational settings (national, regional, and continental). An important implication of all this requires one additional insight: as educators, consultants, and policy advisers, we can assist this process through helping to empower potential entrepreneurs who will be better able to seize opportunities when the environment presents them.

Furthermore, the study represents a significant contribution to our understanding of the methodological and theoretical difficulties associated with this type of evaluation, towards big strategies such as either Africa's Agenda 2063 in light of the sustainable development goals (SDGs) or Africa regional integration (African Union, 2016).

Getting engaged in the International Physical Internet Initiative would enable Africa to conceive and implement interconnected logistics solutions to the situation of each country and region. Overall there is an opportunity for reversing the decaying state of transportation networks and drastically improving the currently weak connectivity. Indeed, taking into account economic, social, and human aspects, the initiative focuses on the logical PI logistics intermediation between geographical points. In this framework, it will therefore be necessary to conduct detailed studies on specific themes in the various sectors related to logistics. This would notably analyze in operational and strategic terms how Africa could progressively implement the Physical Internet on the continent. Air, land, and maritime telecommunication infrastructure should be allowed to assist in the development of Africa through the implementation of the Physical Internet. The primary condition is that the states be involved through their leaders, including private operators on the continent. Beyond the realization of investments for the modernization and rehabilitation of infrastructure in all its forms, the challenge for Africa in the coming decades is to strengthen the interconnection of existing networks. Countries also need to invest in the construction of new lines to avoid traffic congestion and provide circulatory alternatives to develop intra-African and intercontinental trade. As Physical Internet engages in this sense, its planned deployment should be beneficial, yet it will have to overcome numerous challenges. The security challenge is on top of the list. It is not just about terrorism and natural disasters. Aircraft accidents and traffic are likely to disturb the smooth operation of the PI, whose effectiveness lies in a continuous functional system.

Africa will gain from learning the new logistics management within an open and interconnected network. In this research, we briefly discussed why it is necessary to develop competencies to support the implementation of transport infrastructure. But the big question is how we get there from the present position. Though we only touched the surface, this topic could not be substantiated in the absence of precise information and lack of assessment criteria on this. We think it useful to carry out a more elaborate study for that purpose in future. 


\section{References}

Abodohoui, A., da-Silva, I. A., Tossou, G. C. T. M., \& Su, Z. 2014. What are the real chances for Africa to develop its trade? European Journal of Business and Management, 6(33) : 90-99.

ACBF, Fondation pour le Renforcement des Capacités en Afrique. 2016. Impératifs de capacités pour la nouvelle Vision africaine. www.acbf-pact.org.

African Union. 2016. Invest in Africa 2016 - Agenda 2063. London: Newsdesk Media.

Akanni-Honvo, A. 2003. Intégration régionale, effets frontières et convergence ou divergence des économies en développement. Revue Région et développement, 17 : 109-143.

Arvis, J. F., Saslavsky, D., Ojala, L., Shepherd, B., Busch, C., \& Raj, A. 2014. Trade Logistics in the Global Economy: The Logistics Performance Index and its Indicators. Washington D.C., The World Bank.

Ballot, E., \& Fontane, F. 2008. Rendement et efficience du transport: un nouvel indicateur de performance. Revue Française de Gestion Industrielle, 27(2): 41-55.

Burawoy, M. 2005. 2004 American Sociological Association presidential address: for public sociology. The British journal of sociology, 56(2): 259-294.

Carrere, C., \& Grigoriou, C. 2008. Landlockedness, Infrastructure and Trade: New Estimates for Central Asian Countries: CERDI Working Paper.

CEA, Commission économique pour l'Afrique. 2012a. État de l'intégration régionale en Afrique V: Vers une zone de libre-échange continentale africaine. Addis-Abeba, Éthiopie: Commission économique pour l'Afrique.

CEA, Commission économique pour l'Afrique. 2012b. Rapport d'examen africain sur les transports. Addis-Abeba, Éthiopie: Nations Unies Commission économique pour l'Afrique.

Christie, Angela, Don Smith et Kate Conroy. 2013. Indicateurs de gouvernance dans le secteur des transports pour l'Afrique subsaharienne. SSATP Programme de politiques de transport en Afrique, Document de travail No. 95.

CIA. 2013. The World Factbook. Central Intelligence Agency. Washington D.C.

CIDA (The Canadian International Development Agency). 2013. Save the Children Canada. Ottawa, CIDA.

Delamare Le Deist, F. \& Winterton, J. 2005. What is competence? Human Resource Development International, 8(1) : 27-46.

Dépelteau, F. 2000. La démarche d'une recherche en sciences humaines: de la question de départ à la communication des résultats. De Boeck Supérieur.

European Commission. 2003. Commission pushes for an up-date of innovation policies in view of the Spring Council [online] retreived december 10, 2013 http://europa.eu/rapid/press-release IP-03-357 en.htm?locale=en.

FAO. 2013. Stratégie Régionale de Renforcement des Capacités V8. http://www.fao.org/3/a-az432f.pdf. 
Grigoriou, C. 2007. Landlockedness, Infrastructure and Trade: New Estimates for Central Asian Countries. Washington D.C., World Bank. Available at http://english.fsa.ulaval.ca/cms/site/fba/home/faculty/events/IPIC_Conference.

ICA. 2014. Infrastructure Financing Trends in Africa. Tunis Belvedere, Tunisia.

Ika, L. A., \& Donnelly, J. 2017. Success conditions for international development capacity building projects. International Journal of Project Management, 35(1): 44-63.

Klarsfeld, A. 2000. "La compétence : ses définitions, ses enjeux”, Gestion 2000, no. 2 (Mars-Avril) : 31-47.

Lahiri, B., \& Masjidi, F. K. 2012. Landlocked Countries. Journal of Economic Integration, 27(4): 505-519.

Legendre, R. 1988. Dictionnaire actuel de l'éducation Montréal. Larousse: Paris.

Limao, N., \& Venables, A. J. 2001. Infrastructure, geographical disadvantage, transport costs, and trade. The World Bank Economic Review, 15(3): 451-479.

Lombard, M., Snyder-Duch, J., \& Bracken, C. C. 2002. Content analysis in mass communication: Assessment and reporting of intercoder reliability. Human communication research, 28(4): 587-604.

McKinnon, A., \& Ge, Y., et al. 2003. Analysis of transport efficiency in the UK food supply chain. Edinburgh: Logistics Research Centre Heriot-Watt University.

Montreuil, Meller, R. D., \& Ballot, E. 2013. Physical internet foundations. In Service Orientation in Holonic and Multi Agent Manufacturing and Robotics (pp. 151-166), Springer.

Montreuil, B., Rougès, J.-F., Cimon, Y., \& Poulin, D. 2012. The physical internet and business model innovation. Technology Innovation Management Review, 2(6): 32-37.

Montreuil, B. 2011. Toward a physical internet: Meeting the global logistics sustainability grand challenge. Logistics Research, 3(2-3): 71-87.

Ndulu, B. J. 2006. Infrastructure, regional integration and growth in sub-Saharan Africa: Dealing with the disadvantages of geography and sovereign fragmentation. Journal of African Economies, 15(suppl 2): 212-244.

Nilsson, M., Hillman, K., Rickne, A., \& Magnusson, T. (Eds.). 2012. Paving the Road to Sustainable Transport: Governance and Innovation in low-carbon Vehicles. New York: Routledge.

OECD, 2006. The Challenge of Capacity Development: Working Towards Good Practice, DAC Guidelines and Reference Series, Paris: Archieved from the original (PDF) on 28 April 2013.

Okazaki, S. 2004. Does culture matter?: Identifying cross-national dimensions in Japanese multinationals' product-based websites. Electronic Markets, 14(1): 58-69.

Pan, S., Nigrelli, M., Ballot, E., \& Sarraj, R. 2013. Performance assessment of distributed inventory in physical internet. Paper presented at the $43^{\text {rd }}$ International Conference on Computers and Industrial Engineering (CIE43). 
Porter, M. E., \& Stern, S. 2013. Social Progress Index 2013. Washington, DC: Social Progress Imperativ.

Quinet, E., \& Vickerman, R. 2004. Principles of Transport Economics. Cheltenham. New York, Edward Elgar Publishing.

Rodrik, D. 2014. An African Growth Miracle? Economics Working Papers Number 102 : National Bureau of Economic Research.

Rosenberg, M. 1965. Society and the Adolescent Self-image. Princeton University Press, Princeton: NJ.

Sarraj, R., Ballot, E., \& Pan, S. 2012. Potential of routing protocols for freight in open logistics networks: the case of FMCG in France. Paper presented at the $4^{\text {th }}$ International Conference on Information Systems, Logistics and Supply Chain.

Su, Z., Younes, A. B., \& Sorciier, D. P. 1999. La gestion stratégique des relations de partenariat. Partenariats d'entreprises et mondialisation, 95.

Teravaninthorn, S. \& Raballand, G. 2009. Transport prices and costs in Africa : a review of the main international corridors. The International Bank for Reconstruction and Development / The World Bank. DOI: 10.1596/978-08213-7650-8

UA et NEPAD. 2012. Cadre stratégique du renforcement des capacités en Afrique. Agence du NEPAD : Midrand.

UNCTAD. 2010. Transport Newsletter, No. 46 Second Quarter 2010. United Nations Conference on Trade and Development (UNCTAD) Trade Logistics Branch, Division on Technology and Logistics Palais des Nations, Geneva.

UNECA (U.N.Economic Commission on Africa). 2014. Economic Report on Africa 2014. Addis Ababa.

Weber, R. P. 1990. Basic Content Analysis: Sage, Los Angeles: CA.

Wilmsmeier, G., \& Hoffmann, J. 2008. Liner shipping connectivity and port infrastructure as determinants of freight rates in the Caribbean. Maritime Economics \& Logistics, 10(1): 130-151.

World Bank. 2013a. Doing Business 2013-Smarter Regulations for Small and Medium-Size Enterprises. The World Bank. Abgerufen am, 29(04).

World Bank. 2013b. Improving Trade and Transport for Landlocked Developing Countries. World Bank contributions to implementing the Almaty Programme of Action. A report preparing the ten-year comprehensive review. Washington D.C.

World Bank. 2014. Trade Logistics in the Global Economy: The Logistics Performance Index and Its Indicators 2014. The International Bank for Reconstruction and Development/The World Bank.

World Bank. 2008. Improving Trade and Transport for Landlocked Developing Countries. World Bank contributions to implementing the Almaty Programme of Action. A report for the mid-term review. Washington D.C.

Yahmed, D. B., Houstin, N., Pitte, J.-R., \& Cartographie, L. 2011. Atlas de l'Afrique: Jaguar. 
Zekos, G. I. 2004. Ethics versus corruption in globalization. Journal of management development, 23(7): 631-647.

Zhong, R. Y., Huang, G. Q., \& Lan, S. 2014. Shopfloor logistics management using RFID-enabled big data under physical internet. Paper presented at the $1^{\text {st }}$ International Physical Internet Physical Internet Conference (IPIC), Quebec, Canada. 


\section{Annexes}

Table 9. African Countries RIP Ranking.

\begin{tabular}{|c|l|l|l|l|l|l|}
\hline Rank & & & Country & RIP & GDP 2013 & HDI 2013 \\
\hline 1 & Cl6 & & South Africa & 0.645 & 366.06 & 0.66 \\
\hline 2 & $\mathrm{Cl6}$ & & Morocco & 0.645 & 103.72 & 0.62 \\
\hline 3 & $\mathrm{Cl} 5$ & $\star$ & Ghana & 0.562 & 48.59 & 0.57 \\
\hline 4 & $\mathrm{Cl} 5$ & & Rwanda & 0.520 & 7.52 & 0.51 \\
\hline 5 & $\mathrm{Cl} 5$ & & Mauritius & 0.520 & 11.93 & 0.77 \\
\hline & & & & & & \\
\hline
\end{tabular}

\section{Graph 1. Top 10 African Countries.}
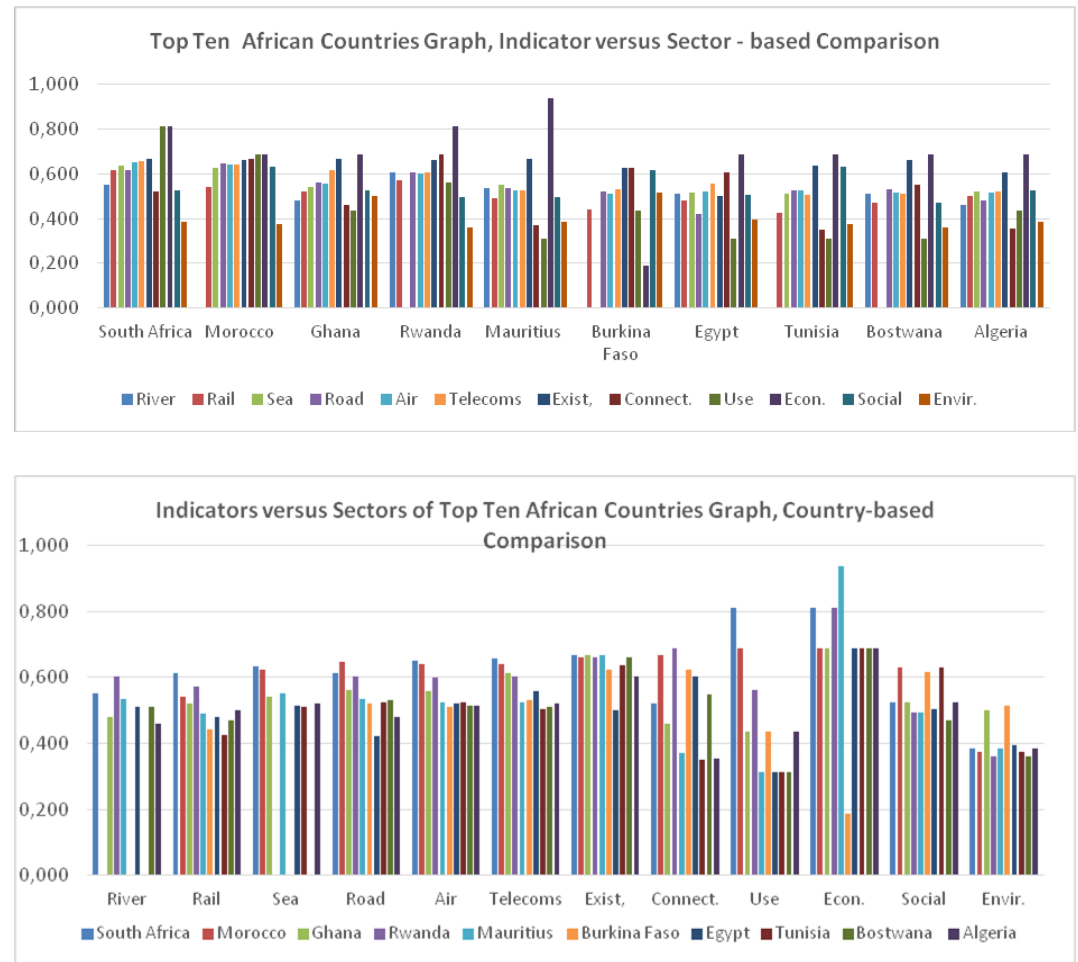